\title{
A Benzoate Coprecipitation Route for Synthesising Nanocrystalline GDC Powder with Lowered Sintering Temperature
}

\author{
Nasrin Ghaemia, Robert C.T. Slade ${ }^{b}$, Bahman Amini Horri ${ }^{*}$ \\ a Department of Chemical and Process Engineering Department, University of Surrey, Guildford GU2 7XH, UK \\ ${ }^{b}$ Department of Chemistry, University of Surrey, Guildford GU2 7XH, UK \\ * Corresponding author: b.aminihorri@surrey.ac.uk
}

\section{Abstract}

Electrolyte powders with low sintering temperature and high-ionic conductivity can considerably facilitate the fabrication and performance of solid oxide fuel cells (SOFCS). Gadolinia-doped ceria (GDC) is a promising electrolyte for developing intermediate- and lowtemperature (IT and LT) SOFCs. However, the conventional sintering temperature for GDC is usually above $1200^{\circ} \mathrm{C}$ unless additives are used. In this work, a nanocrystalline powder of GDC, (10 mol\% Gd dopant, $\mathrm{Gd}_{0.1} \mathrm{Ce}_{0.9} \mathrm{O}_{1.95}$ ) with low-sintering temperature has been synthesized using ammonium benzoate as a novel, environmentally friendly and cost-effective precursor/precipitant. The synthesized benzoate powders (termed washed- and non-washed samples) were calcined at a relatively low temperature of $500{ }^{\circ} \mathrm{C}$ for $6 \mathrm{~h}$. Physicochemical characteristics were determined using thermal analysis (TG/DTA), Raman spectroscopy, FT-IR, SEM/EDX, XRD, nitrogen absorptiometry, and dilatometry. Dilatometry showed that the newly synthesized GDC samples (washed and non-washed routes) start to shrink at temperatures of 500 and $600{ }^{\circ} \mathrm{C}$ (respectively), reaching their maximum sintering rate at 650 and $750{ }^{\circ} \mathrm{C}$. Sintering of pelletized electrolyte substrates at the sintering onset temperature for commercial GDC powder $\left(950^{\circ} \mathrm{C}\right)$ for $6 \mathrm{~h}$, showed densification of washed- and non-washed samples, obtaining 97.48 and $98.43 \%$ respectively, relative to theoretical density. The electrochemical impedance spectroscopy (EIS) analysis for the electrolyte pellets sintered at $950{ }^{\circ} \mathrm{C}$ showed a total electrical conductivity of $3.83 \times 10^{-2}$ and $5.90 \times 10^{-2} \mathrm{~S} \mathrm{~cm}^{-1}$ (under air atmosphere at $750{ }^{\circ} \mathrm{C}$ ) for washed- and non-washed samples, respectively. This is the first report of a GDC synthesis, where a considerable improvement in sinterability and electrical conductivity of the product GDC is observed at $950^{\circ} \mathrm{C}$ without additives addition.

\section{Keywords:}


Solid oxide fuel cell; gadolinium-doped ceria; sintering; low-temperature SOFC electrolyte; environmentally friendly synthesis; ammonium benzoate.

\section{Introduction}

The ever-increasing demand for sustainable, clean, and secure energy sources has caused great interest in fuel cells as the most promising technology for directly converting the chemical energy of fuels to electricity. Among several types of fuel cells, solid oxide fuel cells (SOFCs) offer better fuel versatility, higher electrical efficiency, and less impact on the environment; that make them ideal alternative devices for developing both portable and stationary power systems [1]. SOFCs are fundamentally comprised of three basic components: a dense ceramic electrolyte sandwiched between two porous electrodes (the anode and the cathode). At the cathode (air electrode), oxygen molecules from atmospheric air are electrochemically reduced by electrons supplied from an external circuit to produce oxide ions which migrate through the electrolyte to reach the anode. A fuel gas (usually hydrogen) is electrochemically oxidized at the anode-electrolyte interface (a so-called triple-phase boundary), resulting in water as the product and electrons that pass into the into the external circuit.

The choice of electrolyte is the main factor affecting the operating temperatures of a SOFC. Yttria-stabilized zirconia (YSZ) is the most common electrolyte and cells utilizing YSZ operate at an elevated temperature $\left(800-1000^{\circ} \mathrm{C}\right)$ to ensure an acceptable level of ionic conductivity $\left(10-100 \mathrm{mS} \mathrm{cm}^{-1}\right)$ for the electrolyte $[2,3]$; the ionic conductivity of YSZ at lower temperatures is much less. Costs and materials degradation problems due to such high operating temperatures can be eliminated by lowering the operating temperature; although YSZ offers excellent thermo-mechanical stability in both oxidizing and reducing environments, its requirement of such a high operating temperature accelerates chemical interactions of the cell components [4] and can consequently result in a thermo-chemical degradation of the cell, known to be as one of the main reasons for decreases in cell performance [5]. Great attention has been paid to developing electrolytes for intermediate $\left(600-800^{\circ} \mathrm{C}\right)$, and low-temperature $\left(500-600^{\circ} \mathrm{C}\right)$ use $[6,7]$; doped-ceria oxides are considered one of the most promising due to 
the higher oxygen ion conductivity relative to YSZ in at those temperatures [7, 8]. Gadolinium doped ceria (GDC, $\mathrm{Gd}_{\mathrm{x}} \mathrm{Ce}_{1-\mathrm{x}} \mathrm{O}_{2-\mathrm{x} / 2}, \mathrm{x}=0.1-0.2$ ) is one of the most commonly considered electrolytes for SOFCs operating at intermediate and low-temperature [9].

GDC electrolytes offer excellent ionic conductivity for both intermediate and low operating temperatures [10]., ca. $150 \mathrm{mS} \mathrm{cm}^{-1}$ at $620^{\circ} \mathrm{C}$, a conductivity six times greater than that of YSZ at the same temperature [11]. Oxide ion vacancies in the anion sub-lattice are responsible for ionic conductivity in the fluorite structure of doped-ceria ceramics [12]. Despite their higher ionic conductivity, GDC materials have suffered from poorer densification and sintering properties compared to YSZ. The degree of densification is known to be significantly affected by the applied sintering temperature and the configuration of the grain boundaries in the fabricated ceramic bodies [13].

Several factors such as the shape and density of grain boundaries, the structural disorders, and the presence of impurities in the electrolyte powders can affect the grain boundary resistance of the dense electrolyte pellets [14]. Moreover, the applied synthesis method, the processing conditions, and the dopant concentration and composition can change the properties of the sintered electrolytes and grain boundaries [15].

Many studies have shown that the sintering properties of fabricated ceramics are heavily dependent on the powder's microstructural characteristics such as the particle shape, size, pore-volume, and the number of grain boundaries [16-18]. Particle size reduction using differing synthetic procedures and the addition of sintering aids are the two main approaches that have been widely reported in the literature to improve the densification properties of ceramics [19]. $\mathrm{Li}_{2} \mathrm{CO}_{3}$ has been frequently used as a low melting point additive to reduce the sintering temperature of $\mathrm{Sr}, \mathrm{K}, \mathrm{Nb}(\mathrm{SKN})$-doped piezoelectric ceramics [20-22], $\mathrm{LiBiO}_{2}$ lowers the sintering temperature of $\mathrm{Pb}_{0.95} \mathrm{Ba}_{0.05}\left[\left(\mathrm{Mg}_{1 / 3} \mathrm{Nb}_{2 / 3}\right)_{0.125} \mathrm{Zr}_{0.445} \mathrm{Ti}_{0.43}\right] \mathrm{O}_{3}$ (PBMNZT) ceramics [23], and lithium salts also improve the sintering properties of GDC [24]. Synthesizing ceriabased materials with desirable particle characteristics can be a reliable approach for tailoring the powder characteristics such as particle size, shape and porosity, and also the later ceramic grain boundaries. GDC can be synthesized by a variety of methods (e.g. hydrothermal [25], sol-gel [26], ball milling [27], co-precipitation [28], and combustion [29]), but these methods 
have so far been unable to produce a GDC powder that leads to an adequate level of densification at lower sintering temperatures. A post-synthesis treatment such as ball-milling is usually required to achieve GDC with better sintering properties; for example, sol-gel synthesis and ball milling have been combined to yield GDC powder with a sintering temperature of $1200{ }^{\circ} \mathrm{C}[30]$.

The common preparation of a ceramic electrolyte includes ball-milling of the oxide powder, but the milling produces micro-sized particles, which still require a high sintering temperature to achieve a high-density ceramic piece [31]. In contrast, wet chemical processes such as the Pechini method, co-precipitation, sol-gel thermolysis, glycine-nitrate process, or citric-nitrate combustion can produce high purity, homogeneous, and ultrafine powders at a lower cost. The sintering temperature can be reduced most significantly using a co-precipitation-based synthetic process [32-36], because synthesis route and powder characteristics affect the sinterability, densification and associated kinetic properties [37-39]. Lowering the sintering temperature of GDC without using additives is seen as particularly important because additives can negatively affect the electrical properties of the final ceramic [40]. Coprecipitation is simple, low cost, and easy to perform and can lead to nanoparticulate powders $[39,41]$.

This study developed a simple green method to synthesize nanocrystalline GDC-10 ( $\mathrm{Ce}_{0.9} \mathrm{Gd}_{0.1}$ $\mathrm{O}_{1.95}$ ) powders with, for the first time, sintering temperatures below $1000{ }^{\circ} \mathrm{C}$. A modified carboxylate route has been used for a one-pot co-precipitation, followed by calcination, which leads to nanocrystalline GDC powders, which, when pelletized, show high densification and excellent sinterability at below $1000^{\circ} \mathrm{C}$. A key aspect of its use is that calcination of the firstformed precipitate leads to a pure GDC powder, all other components/residues in the precipitate (benzoate anion, soluble ammonium benzoate co-product and any residual precipitant) being destroyed during calcination. The physicochemical characteristics of the thus synthesized GDC powders have been investigated using a range of instrumental techniques, including thermal analysis (TG/DTA), field emission scanning electron microscopy (FESEM), powder X-ray diffraction (XRD), Raman spectroscopy, and Fourier Transform infrared spectroscopy (FT-IR). The sintering behaviours of fabricated pellets were evaluated using 
thermodilatometry measurements, and the electrochemical properties of the GDC sintered pellets were studied using electrochemical impedance spectroscopy (EIS) analysis.

\section{Materials and Methods}

\subsection{Reagents}

Cerium nitrate $\left(\mathrm{Ce}\left(\mathrm{NO}_{3}\right)_{3} \cdot 6 \mathrm{H}_{2} \mathrm{O}, 99.99 \%\right)$, gadolinium nitrate $\left(\mathrm{Gd}\left(\mathrm{NO}_{3}\right)_{3} \cdot 6 \mathrm{H}_{2} \mathrm{O}, 99.99 \%\right)$, and ammonium benzoate $\left(\mathrm{C}_{7} \mathrm{H}_{5} \mathrm{O}_{2} \mathrm{NH}_{4}, 98 \%\right)$ were all purchased from Sigma Aldrich (Merck) and used as precursors without further purification. All the chemicals and solvents, including acetone, methanol and ethanol, used in this study were of analytical grade' purchased from Sigma Aldrich and used without further purification.

\subsection{Synthesis method}

Commercial GDC-10 powder $\left(\mathrm{CeO}_{2} / \mathrm{Gd}\right.$ with $10 \mathrm{~mol} \% \mathrm{Gd}$ as dopant, < $0.5 \mu \mathrm{m}$ particle size) was obtained from Sigma-Aldrich and used as a comparison material confirming the successful syntheses of nanostructured GDC powders in this study.

Nanocrystalline gadolinium-doped ceria GDC-10 ( $\left.\mathrm{Ce}_{0.9} \mathrm{Gd}_{0.1} \mathrm{O}_{1.95}\right)$ powders were synthesized using a modified carboxylate co-precipitation route with ammonium benzoate as precipitant (see Scheme 1). Stoichiometric amounts of cerium nitrate and gadolinium nitrate were dissolved in deionized water to make a homogeneous solution $\left(0.25 \mathrm{~mol} \mathrm{dm}^{-3}\right)$ which was then added dropwise at the rate of $1 \mathrm{~cm}^{3} \mathrm{~min}^{-1}$ into aqueous ammonium benzoate $\left(0.65 \mathrm{~mol} \mathrm{dm} \mathrm{dm}^{-3}\right.$, in $5 \%$ excess of the stoichiometric amount) with vigorous stirring at room temperature. The resulting solution was stirred $(100 \mathrm{rpm})$ overnight at room temperature to complete the formation of metal (cerium/gadolinium) benzoate. The precipitate was divided into two equal parts; each part separately followed further processing to ultimately produce two different GDC samples, named washed GDC (GDCW) and non-washed GDC (GDC $\left.{ }_{N W}\right)$ powders: 
Washed: the precipitate was recovered using a centrifuge (8000 rpm for $10 \mathrm{~min}$ ). The recovered precipitate was washed repeatedly washed by (i) stirring for 10 min in deionized water followed by centrifugation (8000 rpm, $10 \mathrm{~min}$ ); the washing removes residual coproduct (water-soluble ammonium nitrate) and any residual precipitant.

Non-washed: the reaction mixture (wet, precipitate + some supernatant liquid) was dried using a rotary evaporator ( $\mathrm{BUCHI} \mathrm{R}-100)$ at $50^{\circ} \mathrm{C}$ and at 40 Torr pressure $(1$ Torr $=133.32 \mathrm{~Pa})$.

Calcination to produce GDC powders: The solids produced as above were separately ground using a mortar and pestle, and were then calcined in the air in a muffle furnace at $500^{\circ} \mathrm{C}(6 \mathrm{~h}$ with an initial heating rate of $\left.1.5^{\circ} \mathrm{C} \mathrm{min}-1\right)$, to give samples of $\mathrm{GDC}_{W}$ and $\mathrm{GDC}_{\mathrm{NW}}$ separately

\subsection{Characterization and analysis}

The morphologies of synthesized GDC powders were studied using a field-emission scanning electron microscope (FESEM, JEOL 7100F; 20kV, 8 A) equipped with an EDX detector (Oxford Instruments). Samples were attached to aluminium stubs using conductive carbon glue (TED PELLA, INC- 16035 SDS) followed by sputter coating with a thin layer of gold. The crystallite structure of the products was studied using an X-ray powder diffractometer (PANalytical $X^{\prime}$ Pert3; Cu-K $\alpha$ radiation, $\lambda=1.5406 \AA, 40 \mathrm{kV}$ and $30 \mathrm{~mA}$ ) in the range $20^{\circ} \leq 2 \theta \leq 90^{\circ}$. The Scherrer equation $\left(D_{\mathrm{hkl}}=0.9 \lambda / \beta_{\mathrm{hkl}} \cos \theta\right)$ was used to estimate the crystallite size $D(\mathrm{~nm})$ of the synthesized powders; $\lambda$ is the wavelength $(\mathrm{nm}), \beta$ is the line broadening at half-maximum intensity (FWHM) (radian), and $\theta$ is the Bragg angle. The relevant Bragg equation $\left(\lambda / 2 \sin \theta=a /\left(h^{2}+k^{2}+l^{2}\right)^{1 / 2}\right)$ was also applied to estimate the lattice constant; $a$ is the determined lattice parameter of the cubic crystal, and h, k, and I are the Miller indices for the hkl family of planes. The synthesized powders were studied by Raman spectroscopy in the range of $200-$ $3000 \mathrm{~cm}^{-1}$ using a Thermo DXR2 spectrometer (excitation wavelength $532 \mathrm{~nm}, 8 \mathrm{~mm}$ optical objective 50x). An Agilent Cary 640 FTIR spectrometer was used to record the infrared spectra of the samples in the range $500-4000 \mathrm{~cm}^{-1}$ at $4 \mathrm{~cm}^{-1}$ resolution (32 scans.) 
Calcination and sintering protocols were determined using TG/DTA and thermodilatometry, respectively. Thermogravimetry (TG) was carried out using a TA Instruments SDT-Q600 instrument (room temperature to $900{ }^{\circ} \mathrm{C}$ at $5{ }^{\circ} \mathrm{C} \mathrm{min}-1$ in atmospheric air). The specific surface area for each of the synthesized GDC powders was determined via $\mathrm{N}_{2}$ adsorption/desorption at $77 \mathrm{~K}$, using a Micromeritics 3Flex physisorption unit. Pellets were produced from GDC powders by using a manual hydraulic press (15 MPa pressure) and uniaxial dies of a range of diameters $(\varnothing=3-15 \mathrm{~mm}$ ) to produce button-shape disks (thickness $0.3-0.5 \mathrm{~mm}$ ). Samples of those pellets were sintered at $950^{\circ} \mathrm{C}$ for $6 \mathrm{~h}$ to study their densification at that temperature; the skeletal density of the sample was measured using a helium pycnometer (AccuPyc II 1345, Micromeritics). The apparent density of the pelletized GDC samples (before and after soak sintering) was also estimated using a hand-made device according to ASTM B962-17 method (based on the Archimedes principle). Other pellets were used in thermodilatometric studies; a push-rod vertical dilatometer (NETZSCH, DIL 402C) was used to follow linear shrinkage behaviour (room temperature to $1500{ }^{\circ} \mathrm{C}$, a heating rate $1.5^{\circ} \mathrm{C} \mathrm{min}^{-1}$ in atmospheric air) and to determine the optimal sintering temperature for pelletized GDC powders.

The electrochemical impedance analysis of the samples was conducted using a potentiostat/galvanostat analyzer (Interface 1010E, Gamry, USA), in the frequency range, from $0.1 \mathrm{~Hz}$ to $2 \mathrm{MHz}$, an $\mathrm{AC}$ voltage amplitude of $10 \mathrm{mV}$, and temperatures ranging from 450 ${ }^{\circ} \mathrm{C}$ to $750{ }^{\circ} \mathrm{C}$ in the air atmosphere. Several GDC pellets with the approximate thickness and diameter of $\sim 350 \mu \mathrm{m}$ and $\sim 15 \mathrm{~mm}$ were fabricated by dry-pressing of the calcined GDCNW and GDCW powders at $25 \mathrm{MPa}$ using a manual hydraulic lab press. The button-shape pellets were then sintered at $950^{\circ} \mathrm{C}$ for 6 hours, and silver paste and wire were attached to both sides of the pellet as the current collector. Zview software was used for quantitative analysis of the collected EIS data using a conventional equivalent electronic circuit. The best fit was found to contain three Resistance and three Constant Phase Element (R-CPE) subcircuits in series, which results in three semicircles (arcs) on the typical Nyquist plots. A temperature-dependent Arrhenius conductivity model was used to quantify the electrical conductivity and activation energy of the fabricated GDC pellets as the following equation: 
where $E_{\mathrm{a}}$ is the activation energy required for the electrolyte material, $T$ is the absolute temperature, $k$ is the Boltzmann constant $\left(1.36 \times 10^{-23} \mathrm{~J} / \mathrm{K}\right)$, and $\sigma_{0}$ is a pre-exponential factor representing the intrinsic conductivity of the electrolyte polycrystalline structure. The values of activation energy were estimated using the slope of the linearised form of the Arrhenius equation as follows:

$\log (K)=-E_{a} /\left(2.303^{*} R^{*} T\right)+\log \left(\sigma_{0}\right)$

where $R$ is the universal gas constant $\left(8.314 \mathrm{~J} \cdot \mathrm{K}^{-1} \cdot \mathrm{mol}^{-1}\right)$, and $\log \left(\sigma_{0}\right)$ is the $\mathrm{Y}$-intercepts of the linear Arrhenius plots. The resistance values calculated from simulating the equivalent circuits were used to estimate the bulk conductivity $\left(\sigma_{\text {bulk }}\right)$, the grain-boundary conductivity $\left(\sigma_{\text {grain }}\right.$ boundary), and the total conductivity ( $\sigma_{\text {total }}$ ) of the GDC samples using the following equation: $\sigma=\mathrm{L} / \mathrm{RA}$

Where $\sigma$ is the electrical conductivity, $L$ is the thickness of the prepared GDC pellet, $A$ is the electrode surface area contacting with the GDC pellet (the silver coat), and $R\left(R_{\text {bulk, }}, R_{\text {grain }}\right.$ boundary, and $\left.R_{\text {total }}\right)$ are resistances.

\section{Results and Discussion}

\subsection{Morphological analysis}

A tendency to rapid agglomeration was evident during sample mounting for SEM studies. Fig. 1 presents SEM images for synthesized GDC powders calcined at $500^{\circ} \mathrm{C}$. Results at differing magnifications clearly indicate the formation of nano-sized particles, with measured crystallite sizes in good agreement with sizes estimated using the Scherrer equation. At high magnification, images indicate that all agglomerates consist of microscopic sphere-like particles. $\mathrm{GDC}_{\mathrm{NW}}$ and $\mathrm{GDC}_{\mathrm{W}}$ show particle sizes in the same range (10-16 $\mathrm{nm}$ ), but particles of $\mathrm{GDC}_{W}$ tending to be smaller than those of $\mathrm{GDC}_{\mathrm{NW}}$. During the calcination steps of both routes, the co-precipitate is converted to both the oxide product and gaseous products to produce $\mathrm{GDC}_{W}$. In the production of $\mathrm{GDC}_{\mathrm{NW}}$, residual precipitant (ammonium benzoate) and 
ammonium nitrate co-product are additionally lost, by decomposition and combustion, with consequently increased evolved gas relative to calcination to produce $\mathrm{GDC}_{\mathrm{W}}$; this opens additional microchannels in the structure/texture of the calcine [42] and leads to more isolated particles with small pores between particle agglomerates (as evident in Figure 1b).

\subsection{Structural Characterization and Elemental Analysis}

XRD profiles for GDC samples are shown in Figure 2. GDC has the cubic fluorite $\left(\mathrm{CaF}_{2}\right)$ structure, with space group $F m-3 m$ (no. 225). The XRD profiles for $\mathrm{GDC}_{\mathrm{W}}$ and $\mathrm{GDC}_{\mathrm{NW}}$ are closely similar to that for current commercial GDC; the peaks map very well onto ICDD data (card no. 50-0201) reported for $\mathrm{Gd}_{0.1} \mathrm{Ce}_{0.9} \mathrm{O}_{1.95}$ and $\mathrm{Gd}_{0.2} \mathrm{Ce}_{0.8} \mathrm{O}_{1.9}$ [43]. All peaks in the profiles are assigned/indexed to the fluorite structure, specifically the (111), (200), (220), (311), (222), (400), (331) and (420) reflections [42]. No impurity phase is detected i.e., reaction is complete and produces a single-phase product. The lattice parameter, $a$, determined for the nanocrystalline samples was $5.43 \AA$.

The broader XRD peaks (relative to those for commercial GDC) observed for the nanocrystalline powders resulting from the co-precipitation route demonstrate the formation of particles with smaller crystallite sizes relative to commercial GDC powder. Estimated particle sizes (determined using the most intense peak $\left(2 \theta \approx 28.5^{\circ}\right)$, and assuming no instrumental broadening, are given in Table 1. The obtained crystallite size for both $\mathrm{GDC}_{\mathrm{NW}}$ and GDCw by this method was quite similar (7.5 and $6.3 \mathrm{~nm}$, respectively) and much smaller than that for the commercial sample $(38.5 \mathrm{~nm})$. The average particle size for the synthesized powders was also estimated using a theoretical correlation [particle size $=6$ / (specific surface area $x$ skeletal density)], using the experimental specific surface area and skeletal densities (Table 1). The particle sizes calculated from the surface area correlation were slightly larger than those estimated by Scherrer's equation, but both follow the same trend $\left(G D C_{W}<G D C_{N W}<G D C_{C}\right)$. The larger particle size estimated by surface area correlation in nitrogen absorptiometry could be due to the agglomeration of particles in the bulk of samples 
that prohibits the sorbate from being adsorbed and reached tall of the surface of every single particle.

Figure 2 shows the XRD profiles for both the synthesized GDC samples (after calcination) and the commercial GDC powder $\left(\mathrm{GDC}_{\mathrm{C}}\right)$. GDC has the calcium fluoride $\left(\mathrm{CaF}_{2}\right)$ crystal structure, space group $F m-3 m$ (no. 225). The XRD patterns of the synthesized powders show considerable similarity to that of the commercial powder. The recorded XRD patterns illustrate the presence of the (111), (200), (220), (311), (222), (400), (331) and (420) planes of the cubic fluorite structure [42]. The formation of a single fluorite phase, with no detectable peak relevant to gadolinium oxide, confirms the full substitution of gadolinium into the cerium oxide structure. The peaks obtained map well onto literature XRD patterns, with full compatibility with the ICDD data (card no. 50-0201) reported for both $\mathrm{Gd}_{0.1} \mathrm{Ce}_{0.9} \mathrm{O}_{1.95}$ and $\mathrm{Gd}_{0.2} \mathrm{Ce}_{0.8} \mathrm{O}_{1.9}$ [43]. The broad peaks observed with the synthesized powders indicate the formation of particles with smaller crystal sizes compared to the commercial GDC powder (for which sharper XRD peaks are observed).

The crystallite size and lattice constant of the synthesized GDC powders were estimated by Scherrer's equation and the Bragg equation, respectively (Table 1). The lattice parameter estimated for both the synthesized samples was around $5.43 \AA$, in excellent agreement with the literature value (5.42 ̊from ICDD card no 50-0201) [43]. This confirms the homogeneous dissolution of gadolinium cations in the fluorite structure. The crystallite size was estimated by Scherrer's equation for each sample at the most intense peak, i.e. at $2 \theta \approx 28.5^{\circ}(111)$. The obtained crystallite size for both $\mathrm{GDC}_{\mathrm{NW}}$ and $\mathrm{GDC}_{\mathrm{W}}$ by this method was quite similar $(7.5 \mathrm{~nm}$ and $6.3 \mathrm{~nm}$, respectively) and much smaller than that of the commercial sample (38.5 $\mathrm{nm})$. The average particle size of the synthesized powders was also estimated using a theoretical correlation (particle size $=6 /$ (specific surface area $x$ skeletal density) using the BET specific surface area and skeletal density data (Table 1). The particle sizes calculated from the surface area correlation were slightly larger than those estimated by Scherrer's equation, but both follow the same trend (particle size of $G D C_{W}<G D C_{N W}<G D C_{C}$ ). This larger particle size estimated 
by surface area correlation could be due to the agglomeration of particles in the bulk of samples that prohibits the gas from being adsorbed and reached the surface of every single particle. The manufacturer-reported particle size for the commercial GDC sample was < 100 $\mathrm{nm}$ (with a surface area between $10-14 \mathrm{~m}^{2} / \mathrm{g}$ ), consistent with the particle size results in this study.

Figure 3 shows EDX elemental mapping for the synthesized GDC powders and shows a homogeneous distribution of the different elements at the mesoscale. The theoretical and experimental values for elemental analysis are given in Table 2. The small difference between the mass percentages and those for the perfect crystal is $<2 \%$ for $\mathrm{GDC}_{\mathrm{w}}$. The analyses also clearly show the presence of a lower impurity level (impurities originating in the commercial reagents used) for the $\mathrm{GDC}_{\mathrm{W}}$ sample relative to $\mathrm{GDC}_{\mathrm{NW}}$; the multiple washing steps in preparation of $\mathrm{GDC}_{\mathrm{w}}$ also serve to reduce the level of those impurities.

Raman spectra of the newly synthesized and commercial GDC powders are presented in 4; the spectra for synthesized and commercial samples are very nearly identical. The sharp peak observed at $c a .460 \mathrm{~cm}^{-1}$ corresponds to the $\mathrm{F} 2 \mathrm{~g}$ mode of the fluorite phase [44]. Doping with Gd can shift the F2g peak to slightly lower frequencies, as seen for $\mathrm{GDC}_{\mathrm{NW}}\left(457 \mathrm{~cm}^{-1}\right)$ [42]. The absence of any feature assignable to cubic $\mathrm{Gd}_{2} \mathrm{O}_{3}$ (particularly of a peak at $360 \mathrm{~cm}^{-1}$ diagnostics of that phase) confirms the purities of the GDC solid solutions $[38,45]$, which is also evident from the XRD profiles. In the fluorite structure of ceria, each $\mathrm{Ce}^{4+}$ is linked to four oxide ions, with oxide defects to compensate for the effective negative charge of the dopant cations $\left(\mathrm{Gd}^{3+}\right)$. For GDC samples, the band at $550 \mathrm{~cm}^{-1}$ arises from the oxygen vacancy created by the replacement of $\mathrm{Ce}^{4+}$ with $\mathrm{Gd}^{3+}$, while that at $600 \mathrm{~cm}^{-1}$ bands is linked to the presence of some $\mathrm{M}^{3+}$ ions in the structure [46].

\subsection{Thermogravimetry}

Figure 5 illustrates the thermal analysis (TG/DTA) traces in the air for co-precipitation products. Thermal decomposition of the first-formed benzoate precursors takes place in four 
steps. The initial step is almost completed below $100^{\circ} \mathrm{C}$ and is due [47]; the associated lowintensity endothermic peak is consistent with a slow dehydration rate [48]. The mass loss for both washed and non-washed samples between 100 and $350^{\circ} \mathrm{C}$ (Figure $5 \mathrm{a}$ and $\mathrm{b}$ ) is attributed to the destruction of non-oxide content of the samples; the major exothermic peak below 200 ${ }^{\circ} \mathrm{C}$ in the non-washed sample (Figure $5 \mathrm{a}$ ) is related to the decomposition/oxidation of residues (ammonium nitrate and ammonium benzoate) in the sample, producing $\mathrm{GDC}_{\mathrm{NW}}$. The absence of that peak when producing $\mathrm{GDC}_{W}$ (Fig. b) confirms [49] the effective removal of any accompanying residue (and loss of some impurity content originating in the commercial reagents) through the washing process. The other major exothermic peak for the non-washed co-precipitate, coincident with the only major peak appearing in the thermal profile of the washed co-precipitate, corresponds to thermal oxidation of the benzoate precipitate content in both samples. Both precursor samples, therefore, show a mass-loss above $350^{\circ} \mathrm{C}$ due to that reaction [50], with a slight mass gain $(<1 \%)$ above $400{ }^{\circ} \mathrm{C}$, possibly due to the change of the oxidation state of some of the cerium, from $\mathrm{Ce}^{3+}$ to $\mathrm{Ce}^{4+}[12,51]$. To ensure all reactions were completed, all calculations were performed at $500^{\circ} \mathrm{C}$.

\subsection{Thermodilatometry and densification studies}

The linear shrinkage behaviour of the synthesized and commercial GDC pellets was studied in the range from room temperature to $1500{ }^{\circ} \mathrm{C}$. Figure $6 \mathrm{a}$ and $\mathrm{b}$ show the linear sintering shrinkage and the sintering rate of the samples, respectively. As can be seen in Figure 6a, the $\mathrm{GDC}_{\mathrm{W}}$ and $\mathrm{GDC}_{\mathrm{NW}}$ samples start to shrink at temperatures as low as around 500 and $600{ }^{\circ} \mathrm{C}$, respectively, whereas the sintering onset temperature of the sample is made from the commercial GDC powder is detected at ca. $1000{ }^{\circ} \mathrm{C}$. Further, Figure $6 \mathrm{~b}$ shows that both synthesized GDC materials exhibit a single step densification behaviour, reaching the maximum shrinkage rate around $650{ }^{\circ} \mathrm{C}$ and $750{ }^{\circ} \mathrm{C}$ (for $\mathrm{GDC}_{W}$ and $\mathrm{GDC}_{\mathrm{NW}}$, respectively). In contrast, the commercial GDC powder showed a multistep densification process with a maximum rate occurring at a much higher temperature (ca. $1200^{\circ} \mathrm{C}$ ). 
The low sintering onset temperature obtained for the synthesized GDC powders can be attributed mainly to the perfect number of contact points formed between the particles [34]. The number of contact points between particles heavily depends on the initial particle shape and size in the GDC powder, which depends on the synthesis/processing variables. In the shrinkage plots, it can be seen that both the non-washed and washed GDC samples show another weak broad peak around $1350{ }^{\circ} \mathrm{C}$ and $1450{ }^{\circ} \mathrm{C}$ that may be due to the presence of some hard agglomerates in both samples. At the initial stage of sintering, low-temperature mass diffusion mechanisms mainly control the densification process through the surface and grain boundaries of particles [52]. Comparing the shrinkage rate profiles in Fig. $6 \mathrm{~b}$, the sintering rate of the GDC samples at the initial step can be ordered as $G_{N D C}>G D C_{W}>G D C_{C}$. Based on theories of sintering of ceramic materials, the finer particle size of the powder can result in relatively higher densification levels at lower sintering temperatures [31]. The densification process can then be significantly altered by the pinning effects of porosity during both the intermediate and final stages of sintering [52]. At the highest temperatures (above $1000{ }^{\circ} \mathrm{C}$ ), the shrinkage rate for the samples is in the order $\mathrm{GDC}_{\mathrm{C}}>\mathrm{GDC}_{\mathrm{NW}}>\mathrm{GDC}_{\mathrm{W}}$. The maximum shrinkage of the samples at $1500^{\circ} \mathrm{C}$ approaches similar values (ca. 11\%) for all GDC samples studied, which suggests reaching almost the same microstructure in the final sintered ceramic.

The results of density analyses for sintered pellets are summarized in Table 3 for both synthesized and commercial GDC after sintering. As can be seen in the table, GDCw reached the highest densification ( $98.43 \%$ relative density) recorded for pellets sintered at $950{ }^{\circ} \mathrm{C}$. The results in this table demonstrate the capability of the novel synthesis strategy utilized in this study to prepare a GDC powder with a low sintering temperature and improved densification behaviour (effective sintering at a lower temperature).

\subsection{Microstructural analysis of sintered samples}


Fig. 7 illustrates the cross-section of the $\mathrm{GDC}_{\mathrm{NW}}$ and $\mathrm{GDC}$ w pellets after sintering at $950{ }^{\circ} \mathrm{C}$ for $6 \mathrm{~h}$. The GDC electrolyte pellets were approximately $400 \mu \mathrm{m}$ thick after sintering, showing fully connected particles in the microstructure without major flaws. It can be seen that the electrolyte pellets made from $\mathrm{GDC}_{\mathrm{NW}}$ and $\mathrm{GDC}_{\mathrm{W}}$ have reached high densification levels at 950 ${ }^{\circ} \mathrm{C}$ (ca. 97.48 and $98.43 \%$ relative density, respectively; see Table 3), which confirms the enhanced sinterability of the synthesized GDC pellets. The micrographs confirm that the synthesized GDC powders can be used directly for fabricating SOFC electrolyte layers with acceptable density at a lowered sintering temperature $\left(950{ }^{\circ} \mathrm{C}\right)$. Comparing the microstructures obtained after sintering, the water-washed powder (GDCW) led to sinters with more interconnected particles, with higher densification; this can be linked to the smaller particle size detected in the XRD study of $\mathrm{GDC}_{w}$ powder. Further, the absence of residues (low levels of residual precipitant and co-product) in the pre-calcination material used in producing GDC $C_{W}$ powder (but present in the pre-calcination material leading to $\mathrm{GDC}_{\mathrm{NW}}$ ) results in a better-sintered body with larger grain growth and denser structure, both of which are of great importance in the fabrication of SOFCs.

\subsection{EIS and electrical conductivity analysis}

Figure 8 shows the impedance spectra (Nyquist plot) under the open-circuit condition for the GDCw pellets sintered at $950^{\circ} \mathrm{C}$. The electrochemical impedance data were collected at four different temperatures $\left(450,550,650\right.$, and $750{ }^{\circ} \mathrm{C}$ ) in air. As labelled in Figure $8 \mathrm{a}$, the

impedance spectrum shows three well-distinguished arcs (semicircle) that could be associated with the impedance behaviour of the bulk of grains, the grain boundaries, and the electrolyteelectrode (current collector) interfaces. In the Nyquist plot, the intercept of the impedance arc on the real axis $\left(Z^{\prime}\right)$ at high frequencies represents the ohmic resistance. In contrast, at lower frequencies, the electrolyte-electrode interface impedance tail is often superimposed with the grain-boundary arc [53]. As seen in Figure 8, by increasing the temperature from 450 ${ }^{\circ} \mathrm{C}$ to $550{ }^{\circ} \mathrm{C}$, the impedance arc related to the grain boundaries would be disappeared from the spectrum. Also, above $650^{\circ} \mathrm{C}$, the bulk impedance arc would disappear, as seen in Figure $8 \mathrm{~b}$. These losses of the impedance arcs could be due to the temperature-dependent relaxation 
behaviour of the bulk and the grain boundaries of GDC, along with the impact of experimental apparatus inductances [54]. A naked-eye inspection of the data reported in Figure $8 \mathrm{~b}$ confirms that the GDC pellets ohmic resistances have been considerably decreased by increasing the operating temperature. The ohmic resistance values obtained for the $\mathrm{GDC}_{w}$ pellets at $750^{\circ} \mathrm{C}$ are in line with the results reported in the literature for $\operatorname{GDC}$ powders $[49,55]$. The acquired ohmic resistances summarize the resistances from the bulk of GDC electrolyte, their integrated current collector layers (silver film and paste), and the contact resistance between the current collectors and the measuring instrument electrodes altogether.

The Nyquist plots were further analyzed using the equivalent circuit model inserted in Figure 8 , in which $R$ represents the resistance and CPE (constant phase element) is a non-ideal capacitor. In this model, the capacitance values are associated with charge accumulation in the electrolyte structure; and depending on where it happens, it can represent either the bulk of grains, the grain boundaries, or the electrolyte-electrode interface. Table 4 represents the associated electrical conductivity (bulk conductivity, $\sigma_{b}$; grain-boundary conductivity, $\sigma_{g b}$; and total conductivity, $\sigma_{t}$ ) values estimated by fitting the equivalent circuit impedance response onto the $\mathrm{GDC}_{\mathrm{NW}}$ and $\mathrm{GDC} \mathrm{C}_{\mathrm{W}}$ Nyquist plots. As seen in the table, the electrical conductivity values increase by increasing the operating temperature, which is in accordance with the temperature-dependence conductivity behaviour of the polycrystalline solid electrolytes [56]. Also, a considerable drop in total conductivity is noticeable at low temperature (below 550 $\left.{ }^{\circ} \mathrm{C}\right)$. The bulk conductivity values often correspond to ionic transport within the lattice. In contrast, the magnitude of the grain-boundary conductivity indicates microstructural features impact on the electrolyte ionic transport [57]. As explained, at high temperatures, the presence of bulk and grain boundary arcs often vanish, but the total cell resistance could still be assessed from the high-frequency range of the Nyquist plot.

Figure 9 shows the thermally-activated electrical conductivity plots for both $\mathrm{GDC}_{\mathrm{NW}}$ and $\mathrm{GDC} W$ pellets, where the straight lines are the least-squares fits of the total conductivity data with the linearized form of the Arrhenius equation (Eq. 2). For each plot, data were collected from the GDC pellets sintered at $950^{\circ} \mathrm{C}$ for 6 hours. As seen in Figure 9 , the electrical conductivity values obtained for the washed GDC sample were slightly higher than those of the non- 
washed GDC sample. This is in line with the denser and better microstructural aspects obtained for the washed GDC sample through density measurements (Table 3) and SEM analysis (Figure 7). The results, obtained for both $\mathrm{GDC}_{\mathrm{NW}}$ and $\mathrm{GDC}_{\mathrm{W}}$ samples sintered at $950^{\circ} \mathrm{C}$ for 6 hours in this work, are comparable to the literature data reported for the GDC samples sintered at higher temperatures $\left(1300-1400^{\circ} \mathrm{C}\right)$ or those that have been even measured at slightly higher than $750^{\circ} \mathrm{C}[31,33,58-60]$. For both samples, the bulk and the grain-boundary conductivity dominate the total conductivity in all temperature range. The maximum electrical conductivity obtained for the sintered pellets from $\mathrm{GDC}_{\mathrm{NW}}$ and $\mathrm{GDC}_{\mathrm{W}}$ powders was $3.83 \times 10^{-2}$ and $5.90 \times 10^{-2}{\mathrm{~S} . \mathrm{cm}^{-1}}$ at $750{ }^{\circ} \mathrm{C}$ with an activation energy of 0.60 and $0.67 \mathrm{eV}$, respectively. The activation energy values obtained for the washed sample is quite comparable with the results reported in previous works $[55,59]$. The higher activation energy obtained for the non-washed sample could be due to the additional grain boundary resistance for this sample, which has been observed in other ceria-based materials reported in the literature as well [61, 62].

\section{Conclusions}

Nanocrystalline GDC-10 $\left(\mathrm{Ce}_{0.9} \mathrm{Gd}_{0.1} \mathrm{O}_{1.95}\right)$ powders with excellent sintering behaviour at $\mathrm{T}<$ $1000{ }^{\circ} \mathrm{C}$ were synthesized using a modified carboxylate route. Ammonium benzoate $\left(\mathrm{C}_{7} \mathrm{H}_{5} \mathrm{O}_{2} \mathrm{NH}_{4}\right)$ was used as a green precipitant for low-cost synthesis. Two routes, namely a "washed" route (via a residue-free benzoate co-precipitate) and a "non-washed" route (via a benzoate co-precipitate containing ammonium nitrate and excess precipitant residues) were prepared by calcining the benzoate co-precipitate at $500{ }^{\circ} \mathrm{C}$ for $6 \mathrm{~h}$. The physicochemical characteristics and sintering behaviour of the synthesized GDC powders were compared with a commercial GDC powder (GDC $)$. Thermal analysis showed that the metal (Ce/Gd)-benzoate co-precipitate is fully converted to GDC powder at $\mathrm{T}<500^{\circ} \mathrm{C}$, after up to four mass-loss steps. A particle size analysis based on nitrogen absorptiometry and XRD results revealed that the synthesized GDC powders had a smaller particle size $(5-15 \mathrm{~nm})$ relative to a commercial sample $(50-100 \mathrm{~nm})$. The densification behaviour for pellets of the synthesized GDC powders was studied by thermodilatometry and soak sintering. Pellets formed from synthesized GDC 
powders showed a single step densification behaviour and reached their maximum shrinkage rate around 650 and $750{ }^{\circ} \mathrm{C}$ for $\mathrm{GDC}_{\mathrm{W}}$ and $\mathrm{GDC}_{\mathrm{NW}}$, respectively, to give relative densities as high as $97.48 \%\left(\mathrm{GDC}_{\mathrm{NW}}\right)$ and $98.43 \%(\mathrm{GDC})$ after sintering at $950^{\circ} \mathrm{C}$ for $6 \mathrm{~h}$. The benzoate co-precipitation method leads to a GDC powder with a "perfect number" of contact points between its particles that is evident in obtaining a lowered sintering temperature and sinters of high relative density. The electrical conductivity showed that the synthesized GDC powders are promising electrolyte material for LT-SOFC applications with the conductivity of $3.83 \times 10^{-}$ 2, and $5.90 \times 10^{-2} \mathrm{~S} \mathrm{~cm}^{-1}$ at $750{ }^{\circ} \mathrm{C}$ and an activation energy of 0.60 and $0.67 \mathrm{eV}$ for $\mathrm{GDC}_{\mathrm{NW}}$ and $G D C_{W}$, respectively.

\section{Acknowledgements}

The authors thank the Department of Chemical and Process Engineering (CPE) at the University of Surrey and the Royal Society Research Grant RGS\R2\202137 for financial support. The authors also thank Ben Gibbons and Thomas Chamberlain (both of CPE) and David Jones (Department of Mechanical Engineering Sciences) for their technical and experimental support. 


\section{Tables}

Table 1. The crystal size, lattice parameter and BET specific surface area for synthesized and commercial GDC powders

\begin{tabular}{ccccc}
\hline \multirow{2}{*}{$\begin{array}{c}\text { Sample } \\
\text { ID }\end{array}$} & Lattice parameter & Specific surface area & \multicolumn{2}{c}{ Particle size $(\mathbf{n m})$} \\
\cline { 4 - 5 } & $(\AA)$ & $\left(\mathbf{m}^{\mathbf{2}} \mathbf{~}^{-1}\right)$ & Scherrer's equation & $\begin{array}{c}\text { Nitrogen } \\
\text { absorptiometry }\end{array}$ \\
\hline GDC $_{\text {NW }}$ & 5.4258 & 53.5 & 7.5 & 16.1 \\
GDC $_{W}$ & 5.4258 & 57.3 & 6.3 & 14.6 \\
GDC & $5.4180[28]$ & $10-14[49]$ & 58.5 & 76.8 \\
\hline
\end{tabular}

Table 2. The EDX elemental analysis results for the synthesized GDC powders

\begin{tabular}{ccccccc}
\hline \multirow{2}{*}{ Element } & \multicolumn{3}{c}{ Mass (\%) } & & \multicolumn{2}{c}{ Error (\%) } \\
\cline { 2 - 4 } \cline { 5 - 6 } & $\mathrm{GDC}_{\mathrm{NW}}$ & $\mathrm{GDC}$ & $\mathrm{GDC}-10$ & & \multirow{2}{*}{$\mathrm{GDC}_{\mathrm{NW}}$} & $\mathrm{GDC}_{\mathrm{W}}$ \\
\hline $\mathrm{Ce}$ & 70.13 & 71.91 & 72.88 & & 2.91 & 1.33 \\
$\mathrm{Gd}$ & 8.84 & 8.94 & 9.09 & & 2.75 & 1.65 \\
$\mathrm{O}$ & 17.51 & 17.79 & 18.03 & & 2.88 & 1.33 \\
Impurities & 3.52 & 1.36 & 0 & & - & - \\
\hline
\end{tabular}

Table 3. The apparent, skeletal, and relative density data for sintered pellets of synthesized and commercial GDC powders

\begin{tabular}{ccccc}
\hline $\begin{array}{c}\text { Sample } \\
\text { ID }\end{array}$ & $\begin{array}{c}\text { Sintering } \\
\text { temperature } \\
\left({ }^{\circ} \mathrm{C}\right)\end{array}$ & $\begin{array}{c}\text { Apparent density } \\
\text { from ASTM B962-17 } \\
\left(\mathbf{g ~ c m}^{-3}\right)\end{array}$ & $\begin{array}{c}\text { Skeletal density from } \\
\text { helium pycnometry } \\
\left(\mathrm{g} \mathrm{cm}^{-3}\right)\end{array}$ & $\begin{array}{c}\text { Relative } \\
\text { density } \\
\text { (\%) }\end{array}$ \\
\hline GDC $_{\mathrm{NW}}$ & 950 & 6.97 & 7.15 & 97.48 \\
$\mathrm{GDC}_{w}$ & 950 & 6.98 & 7.09 & 98.43 \\
GDC $_{\mathrm{C}}$ & 950 & 6.01 & 6.50 & 92.34 \\
\hline
\end{tabular}


Table 4. Electrical conductivity at different temperatures for the synthesized GDC powders

\begin{tabular}{|c|c|c|c|}
\hline $\begin{array}{c}\text { Electrical } \\
\text { conductivity* }\end{array}$ & Temperature $\left({ }^{\circ} \mathrm{C}\right)$ & $\mathrm{GDC}_{\mathrm{NW}}$ & $\mathrm{GDC}_{\mathrm{w}}$ \\
\hline \multirow{4}{*}{$\sigma_{b}\left(S . \mathrm{cm}^{-1}\right)$} & 450 & $5.85 \mathrm{E}-03$ & $2.70 \mathrm{E}-02$ \\
\hline & 550 & $1.07 E-02$ & 4.95E-02 \\
\hline & 650 & 5.00E-02 & $8.59 \mathrm{E}-02$ \\
\hline & 750 & $7.62 \mathrm{E}-02$ & 1.13E-01 \\
\hline \multirow{4}{*}{$\sigma_{\mathrm{gb}}\left(\mathrm{S} . \mathrm{cm}^{-1}\right)$} & 450 & $3.20 \mathrm{E}-03$ & $7.78 \mathrm{E}-03$ \\
\hline & 550 & $9.14 \mathrm{E}-03$ & $2.16 \mathrm{E}-02$ \\
\hline & 650 & 3.67E-02 & $6.10 \mathrm{E}-02$ \\
\hline & 750 & 7.69E-02 & $1.08 \mathrm{E}-01$ \\
\hline \multirow{4}{*}{$\sigma_{t}\left(S . \mathrm{cm}^{-1}\right)$} & 450 & 2.07E-03 & $6.04 \mathrm{E}-03$ \\
\hline & 550 & 4.94E-03 & $1.50 \mathrm{E}-02$ \\
\hline & 650 & $2.12 \mathrm{E}-02$ & $3.57 \mathrm{E}-02$ \\
\hline & 750 & $3.83 \mathrm{E}-02$ & $5.90 \mathrm{E}-02$ \\
\hline
\end{tabular}

* The electrical conductivity measurement average error: $\pm 0.01 \%$ 


\section{Figures}
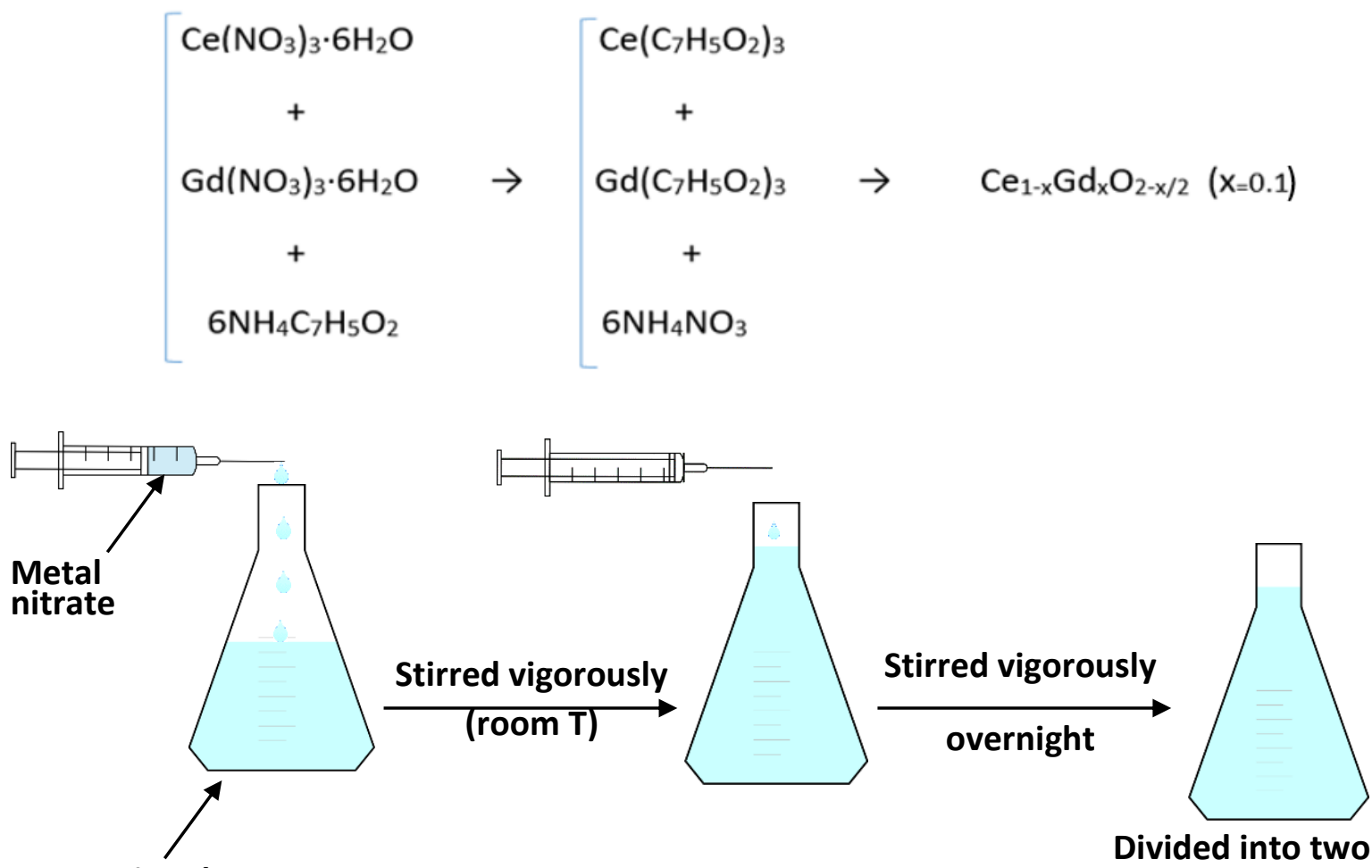

Ammonium benzoate

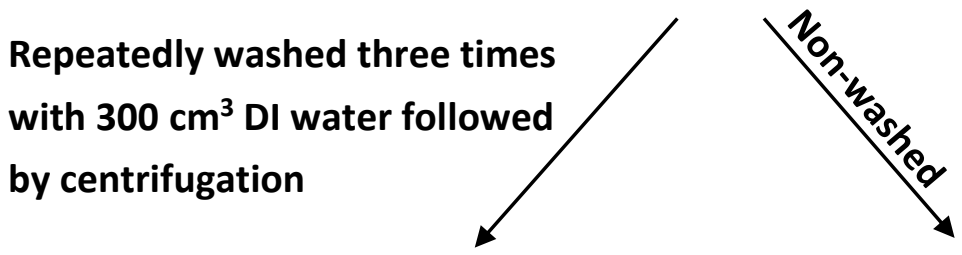

- Vacuum rotatory evaporation

- Dried under vacuum at $50^{\circ} \mathrm{C}$

- Finely ground and calcined at $500{ }^{\circ} \mathrm{C}$
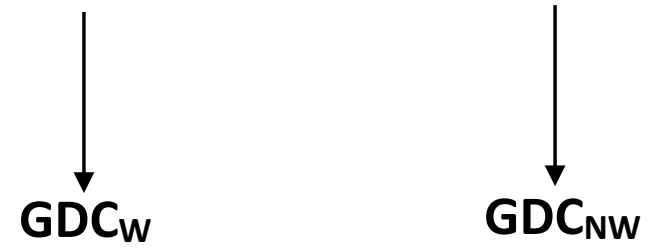

Scheme 1. The reaction and processing steps used in the modified carboxylate route with ammonium benzoate as the precipitant 

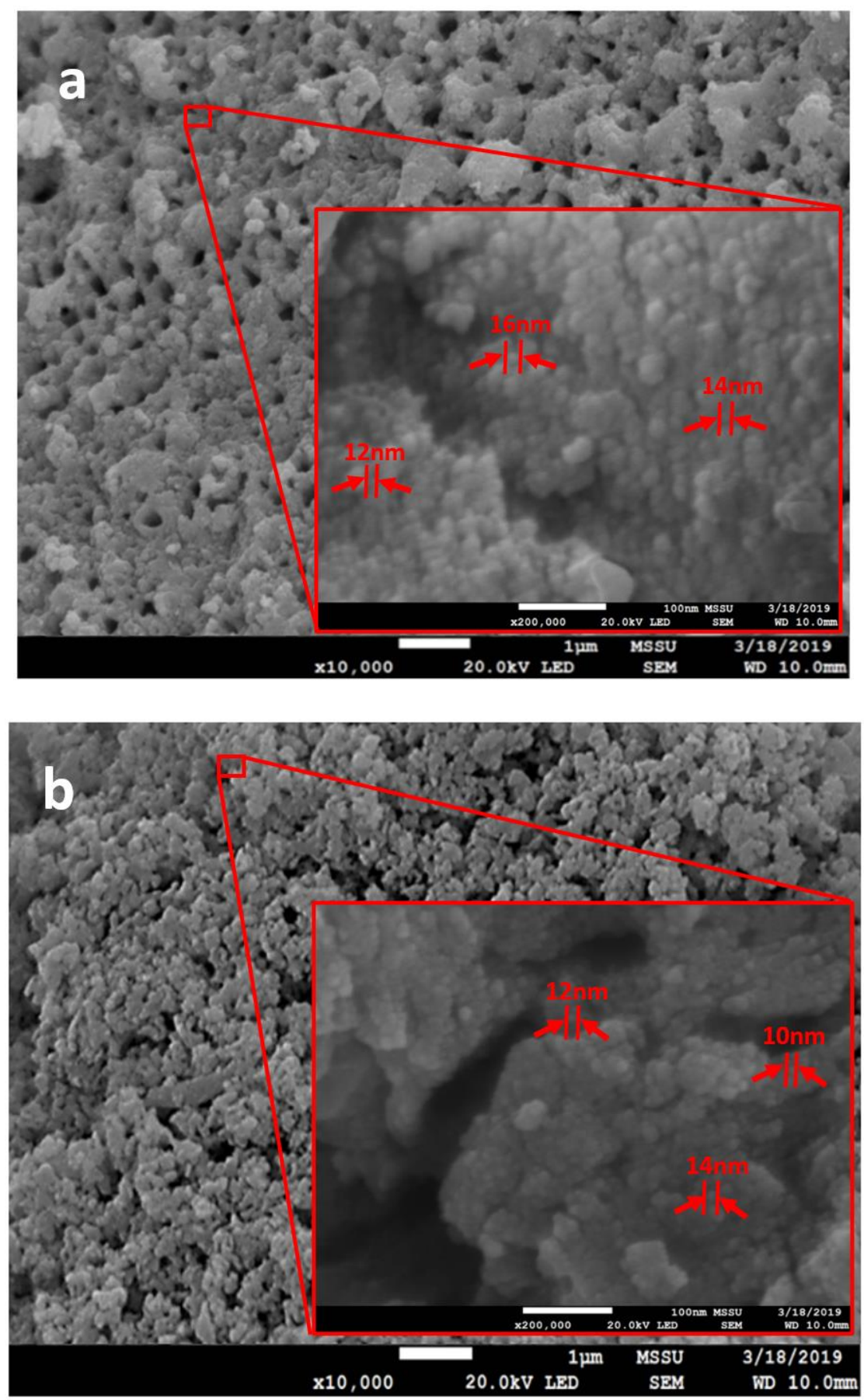

Fig. 1. FESEM micrographs of the synthesized GDC powders after calcination at $500^{\circ} \mathrm{c}$ for $6 \mathrm{~h}$ : a) $\mathrm{GDC}_{\mathrm{NW}}$; b) $\mathrm{GDC}_{\mathrm{W}}$ 


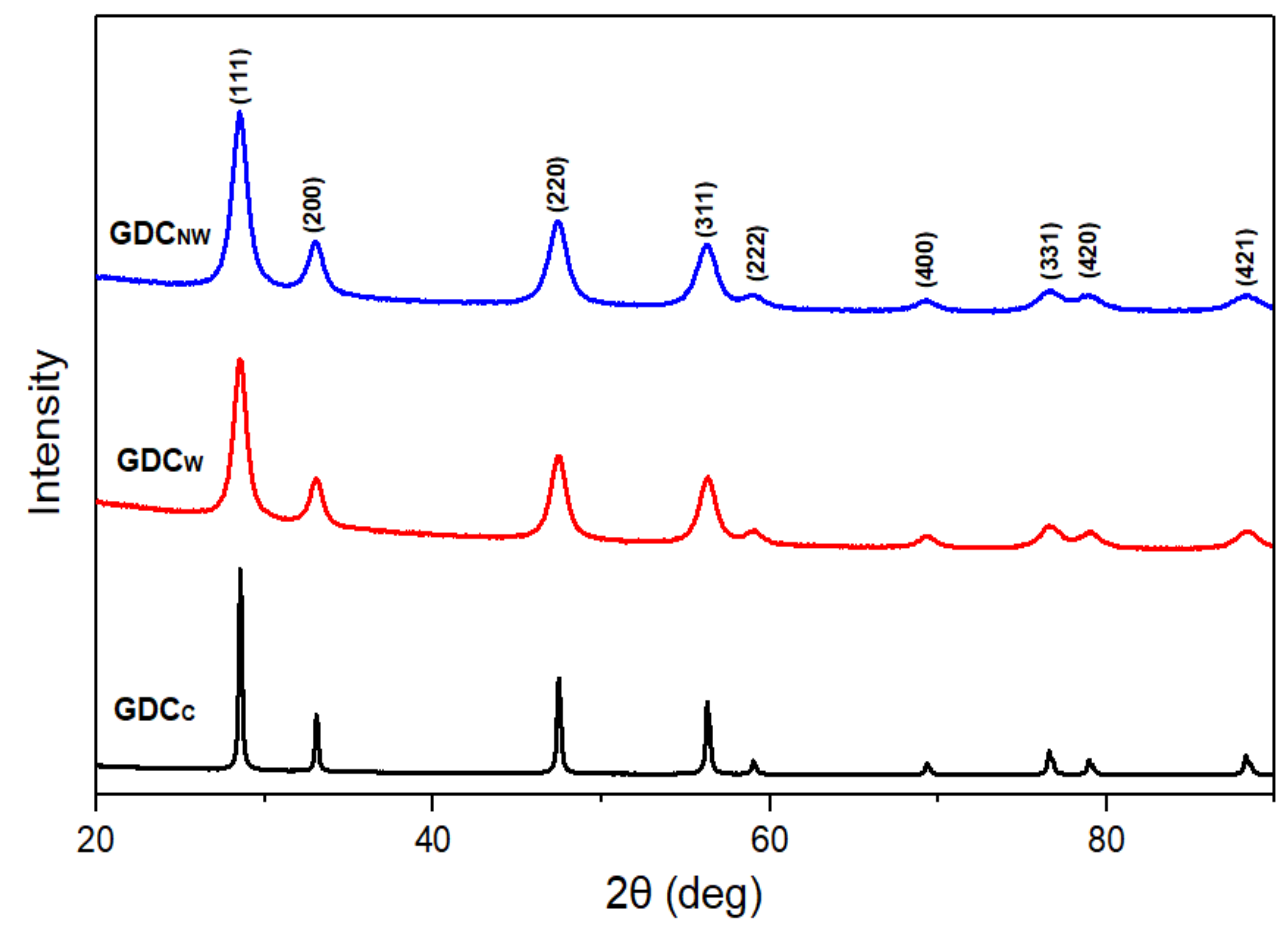

Fig. 2. XRD profiles for the synthesized GDC powders (calcined at $500{ }^{\circ} \mathrm{C}$ for $6 \mathrm{~h}$ ) along with that for commercial GDC $\left(G_{C}\right)$
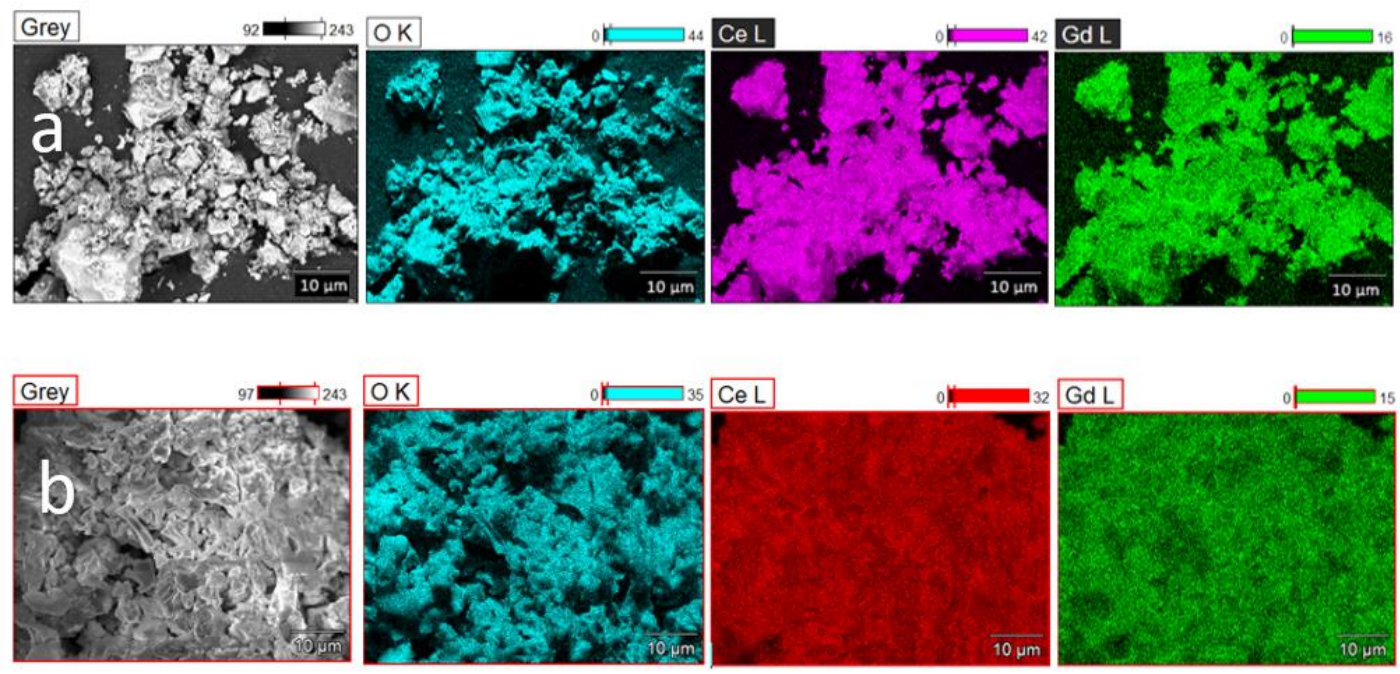

Fig. 3. EDX elemental maps for the synthesized GDC powders: a) $G D C_{N w}$; b) $G D C_{W}$ 


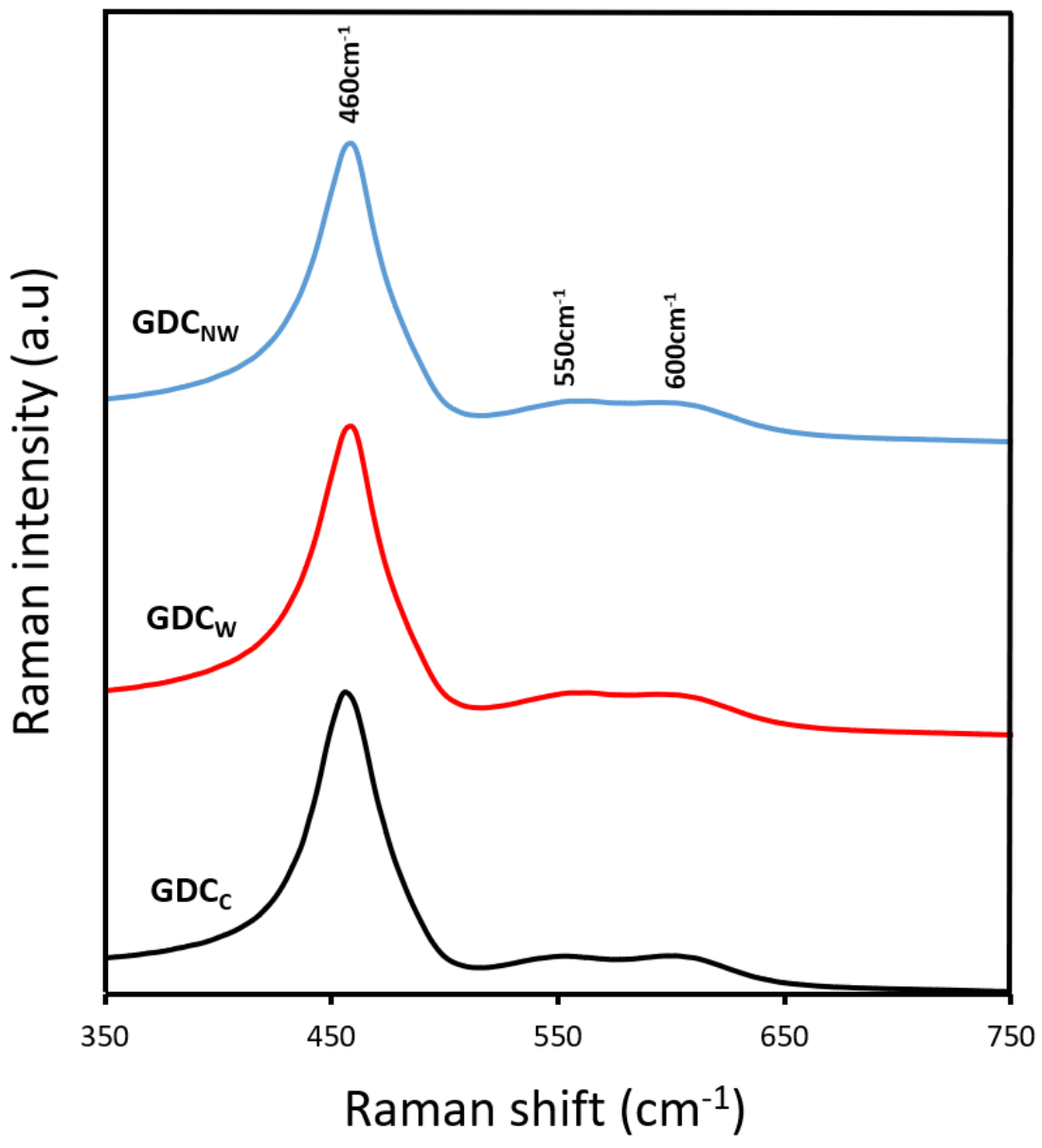

Fig. 4. Raman spectra collected for synthesized and commercial GDC powders: a) $G_{D C} C_{N w}$ b) GDC ; C) $\mathrm{GDC}_{\mathrm{c}}$ 

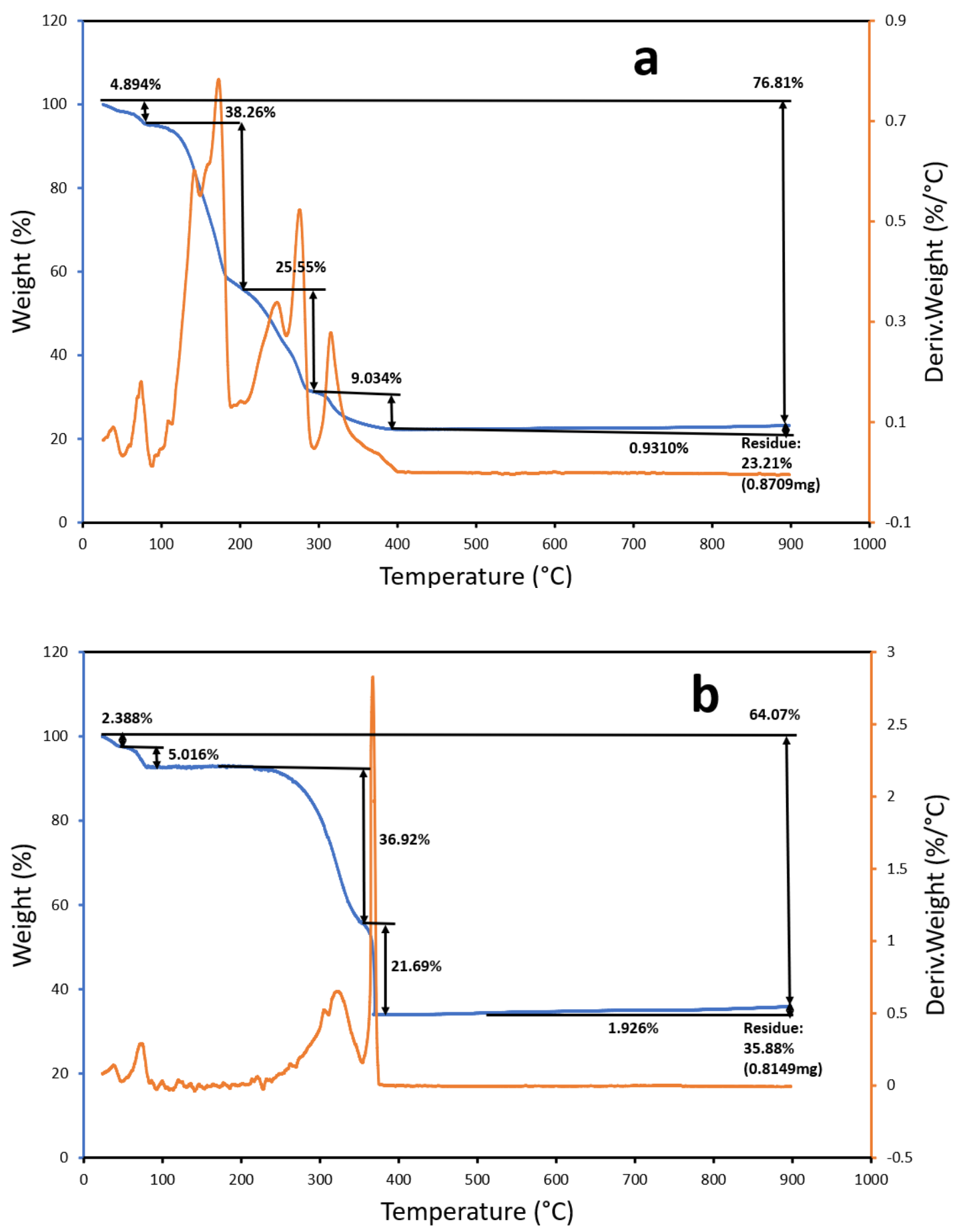

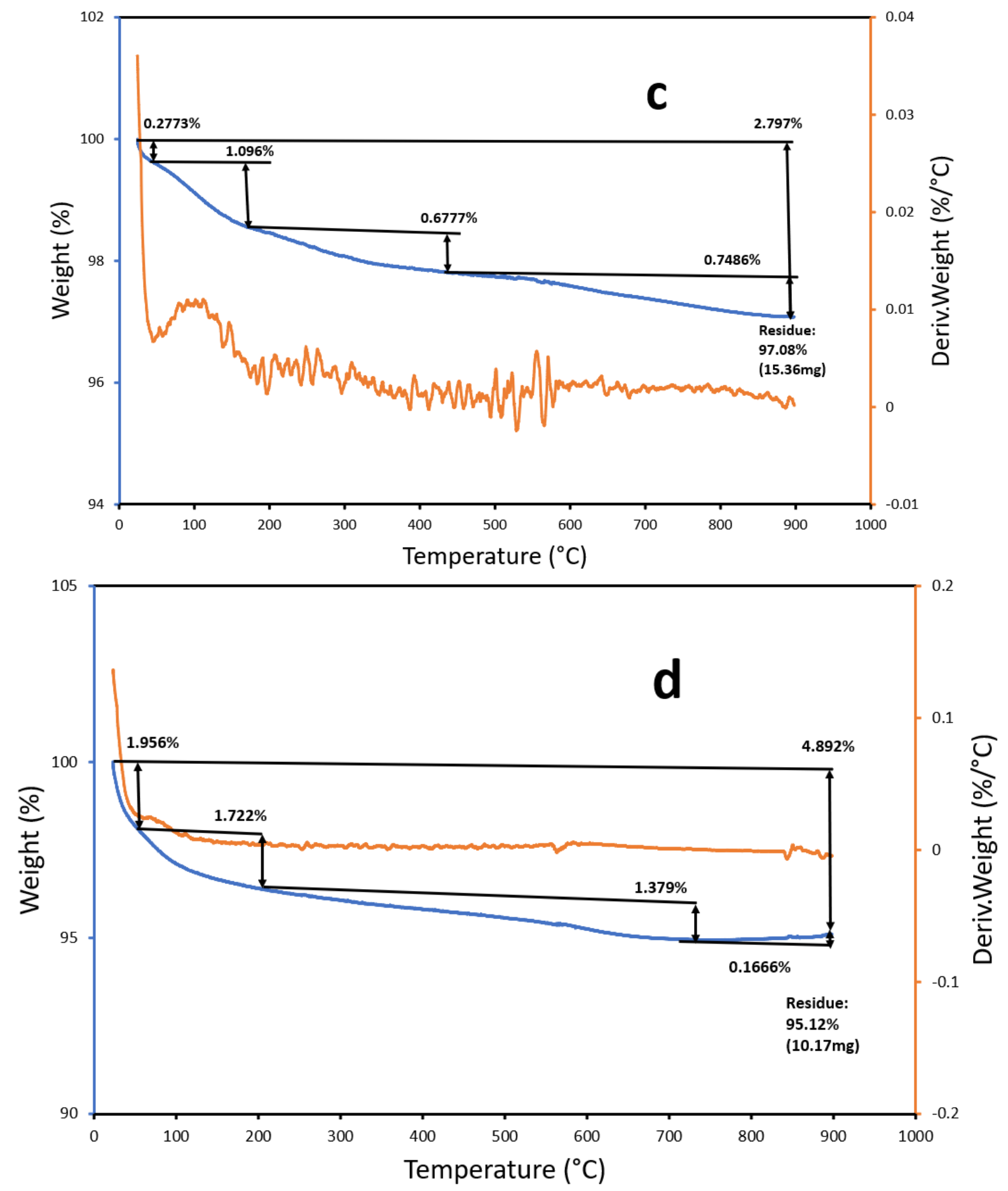

Fig. 5. Thermogravimetry results for the synthesized GDC powders in the air: a) $G D C_{N w}$ before calcination; b) $\mathrm{GDC}_{\mathrm{w}}$ before calcination; c) $\mathrm{GDC}_{\mathrm{Nw}}$ after calcination; d) $\mathrm{GDC}_{\mathrm{w}}$ after calcination, at $500{ }^{\circ} \mathrm{C}$ for $6 \mathrm{~h}$ 

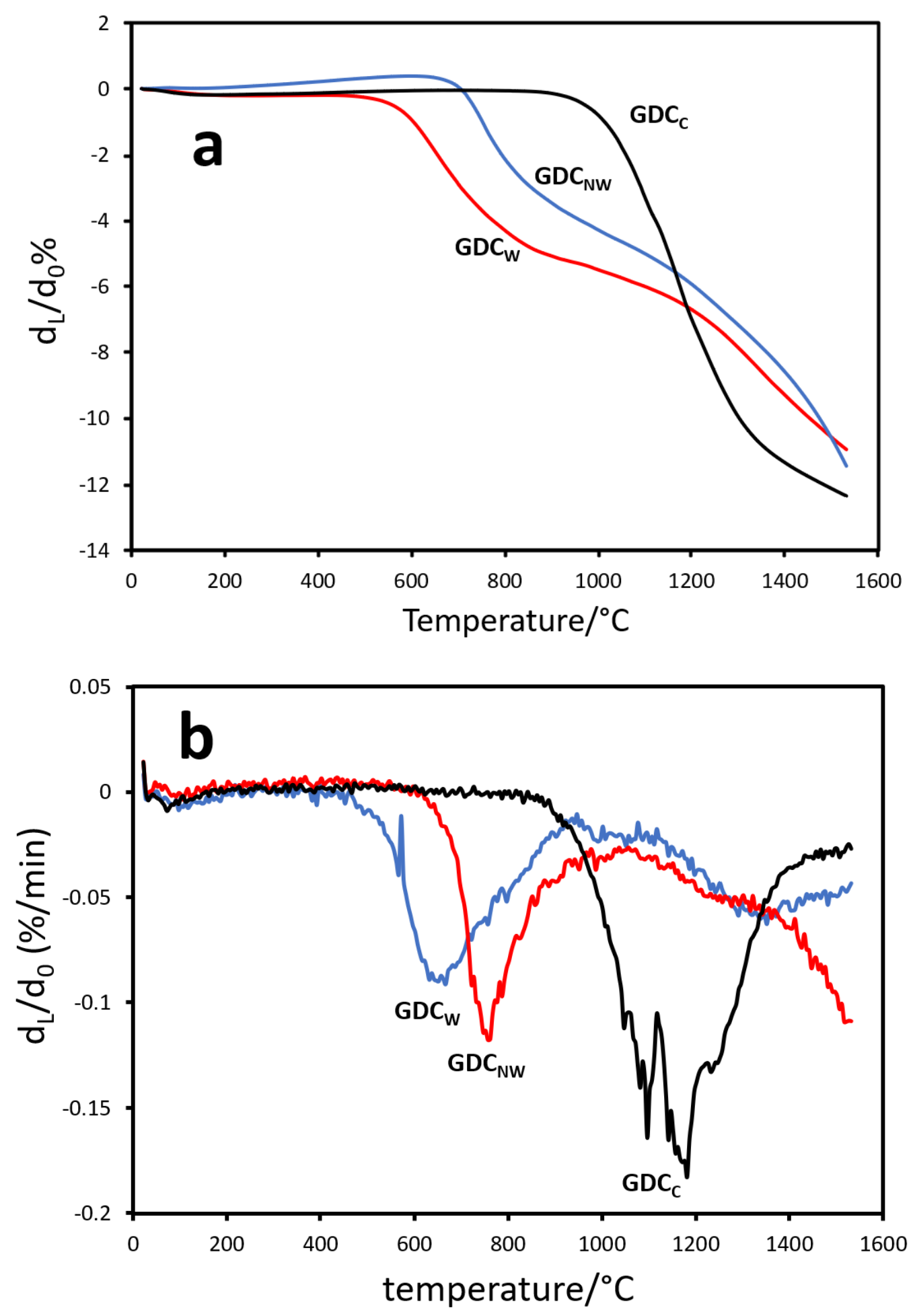

Fig. 6. a) The linear shrinkage, and b) the shrinkage rate for pellets of synthesized and commercial $\mathrm{GDC}$ powders heated from room temperature to $1500^{\circ} \mathrm{C}$ 

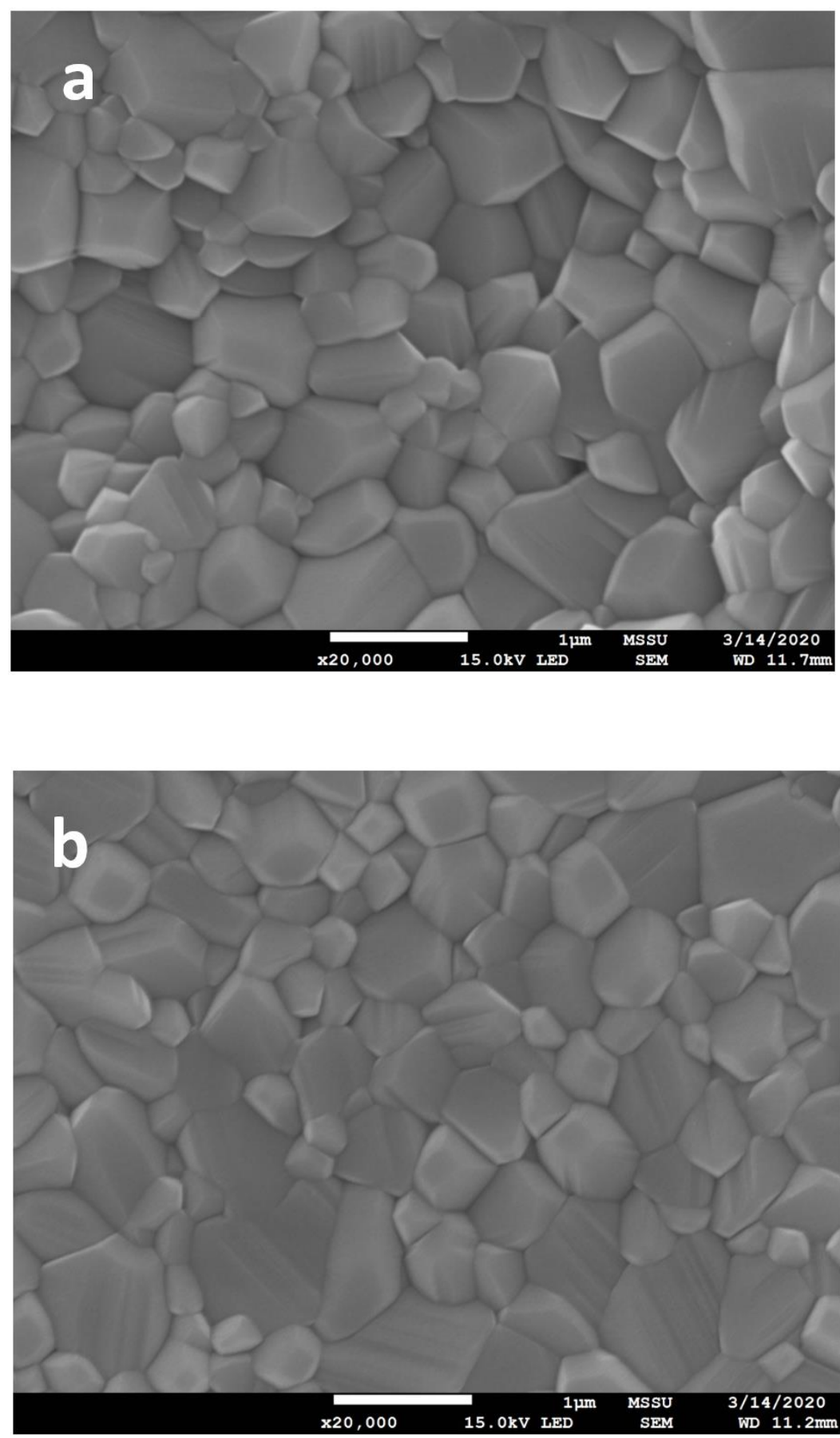

Fig. 7. FESEM images of the GDC pellets after sintering at $950^{\circ} \mathrm{C}$ for $6 \mathrm{~h}$ : a) $\mathrm{GDC}_{\mathrm{w}}$; b) $\mathrm{GDC}_{\mathrm{NW}}$ 


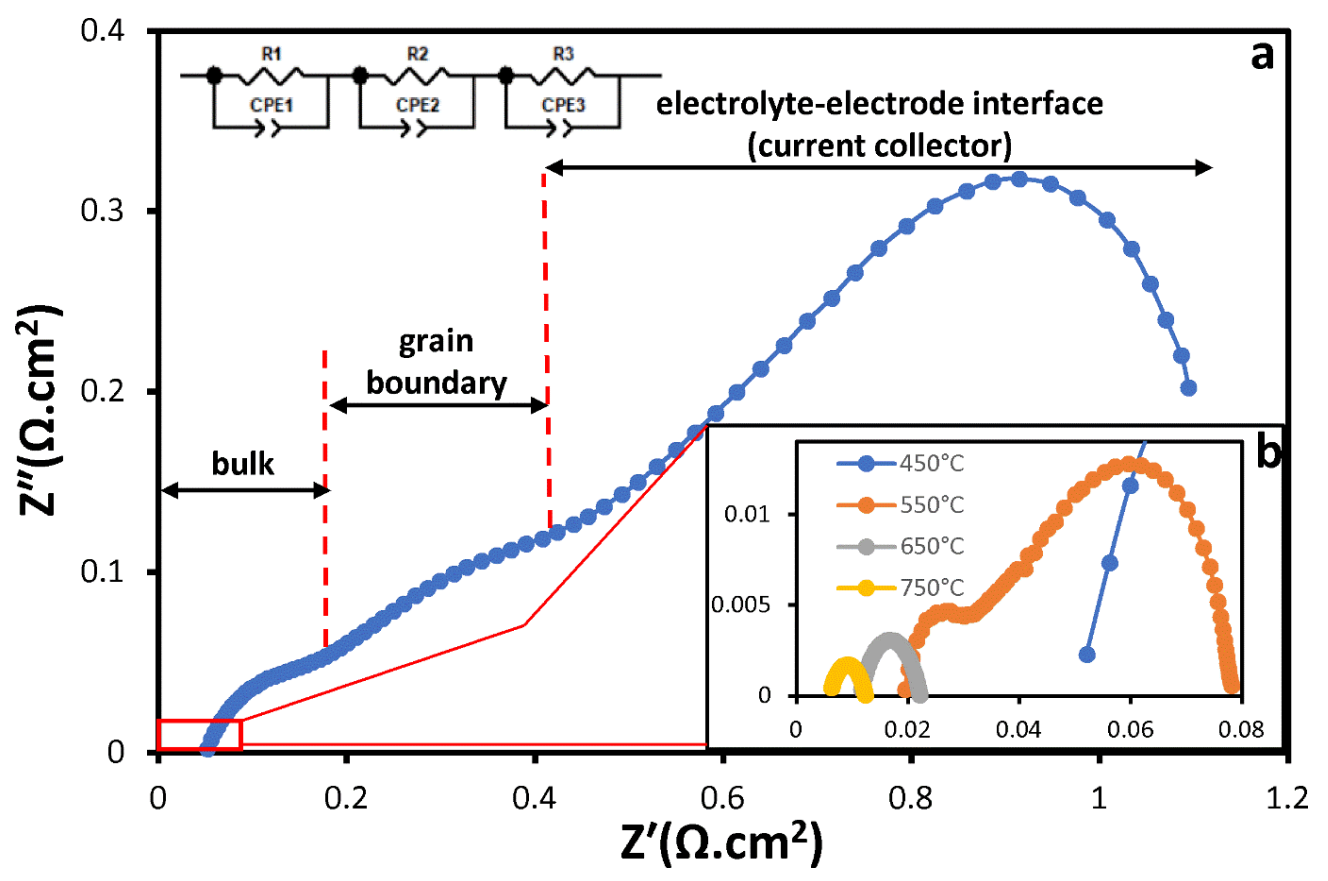

Fig 8. Impedance spectra of synthesised GDC measured at (a) $450^{\circ} \mathrm{C}$ and (b) $450-750^{\circ} \mathrm{C}$ in air. Temperature $\left({ }^{\circ} \mathrm{C}\right)$

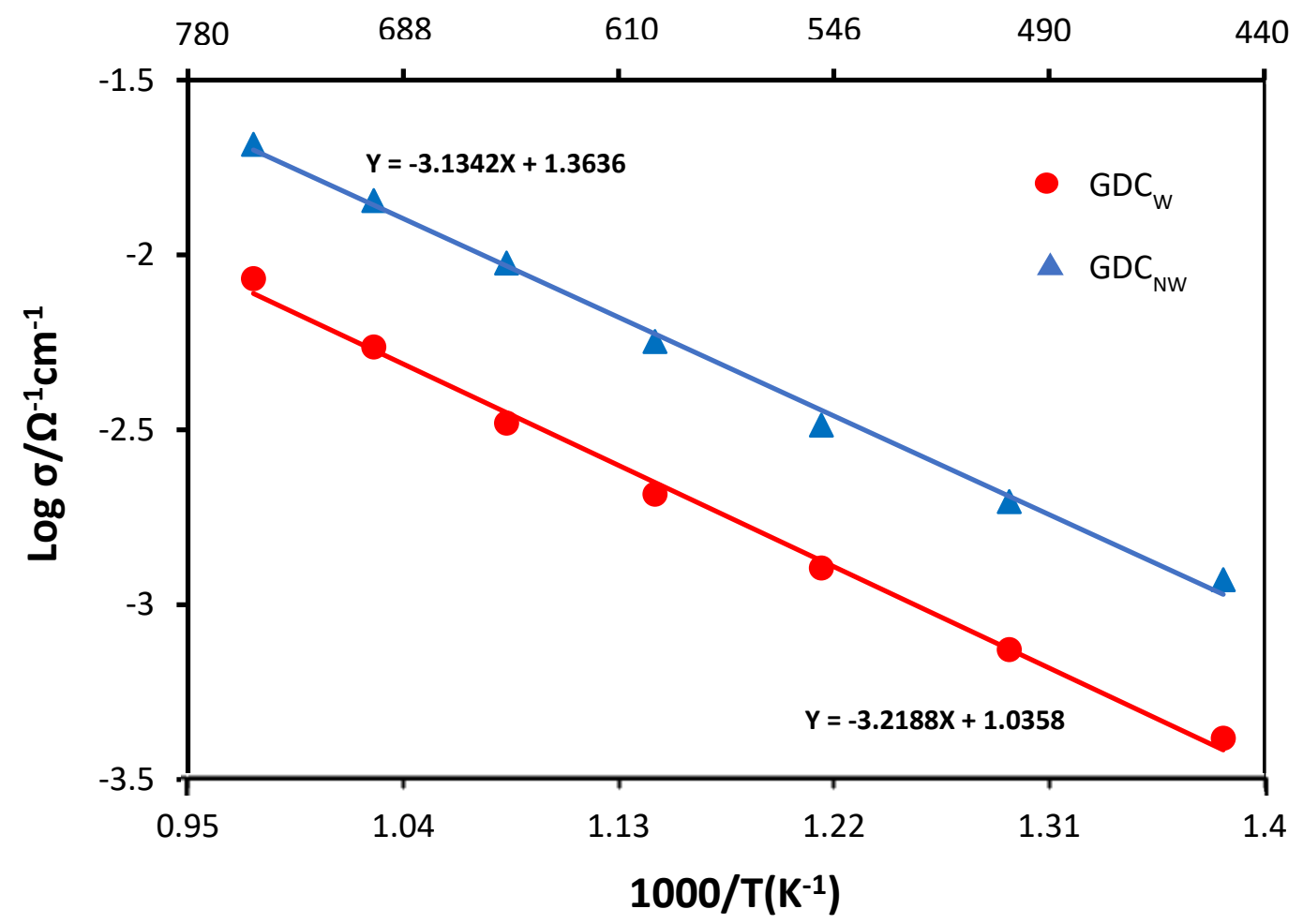

Fig 9. Ionic conductivity data of synthesised GDC pellet sintered at 950 


\section{References}

[1] M. Fallah Vostakola, B. Amini Horri, Progress in Material Development for Low-Temperature Solid Oxide Fuel Cells: A Review, Energies, 14 (2021) 1280.

[2] I. Kosacki, C.M. Rouleau, P.F. Becher, J. Bentley, D.H. Lowndes, Nanoscale effects on the ionic conductivity in highly textured YSZ thin films, Solid State lonics, 176 (2005) 1319-1326.

[3] B.A. Horri, C. Selomulya, H. Wang, Electrochemical characteristics and performance of anodesupported SOFCs fabricated using carbon microspheres as a pore-former, International journal of hydrogen energy, 37 (2012) 19045-19054.

[4] E. Ivers-Tiffée, A. Weber, D. Herbstritt, Materials and technologies for SOFC-components, Journal of the European Ceramic Society, 21 (2001) 1805-1811.

[5] Y. Mishima, Solid Oxide Fuel Cell with Composite Electrolyte Consisting of Samaria-Doped Ceria and Yttria-Stabilized Zirconia, Journal of The Electrochemical Society, 145 (1998) 1004.

[6] A. Tarancón, Strategies for Lowering Solid Oxide Fuel Cells Operating Temperature, Energies, 2 (2009) 1130-1150.

[7] C. Kleinlogel, L.J. Gauckler, Sintering and properties of nanosized ceria solid solutions, Solid State lonics, 135 (2000) 567-573.

[8] M. Choolaei, B.A. Horri, Catalytic Aspects of Fuel Cells: Overview and Insights, Heterogeneous Catalysis for Energy Applications, (2020) 459.

[9] S. Piñol, M. Morales, F. Espiell, Low temperature anode-supported solid oxide fuel cells based on gadolinium doped ceria electrolytes, Journal of power sources, 169 (2007) 2-8.

[10] M.S. Anwar, S. Kumar, N. Arshi, F. Ahmed, Y.J. Seo, C.G. Lee, B.H. Koo, Structural and optical study of samarium doped cerium oxide thin films prepared by electron beam evaporation, Journal of Alloys and Compounds, 509 (2011) 4525-4529.

[11] A.B. Stambouli, E. Traversa, Solid oxide fuel cells (SOFCs): a review of an environmentally clean and efficient source of energy, Renewable and Sustainable Energy Reviews, 6 (2002) 433-455.

[12] T. Mahata, G. Das, R.K. Mishra, B.P. Sharma, Combustion synthesis of gadolinia doped ceria powder, Journal of Alloys and Compounds, 391 (2005) 129-135.

[13] J.E. Burke, Role of Grain Boundaries in Sintering, Journal of the American Ceramic Society, 40 (1957) 80-85.

[14] D.W. Joh, M.K. Rath, J.W. Park, J.H. Park, K.H. Cho, S. Lee, K.J. Yoon, J.-H. Lee, K.T. Lee, Sintering behavior and electrochemical performances of nano-sized gadolinium-doped ceria via ammonium carbonate assisted co-precipitation for solid oxide fuel cells, Journal of Alloys and Compounds, 682 (2016) 188-195.

[15] O.N. Verma, N.K. Singh, P. Singh, Study of ion dynamics in lanthanum aluminate probed by conductivity spectroscopy, RSC Advances, 5 (2015) 21614-21619.

[16] R. Bjørk, V. Tikare, H.L. Frandsen, N. Pryds, The Effect of Particle Size Distributions on the Microstructural Evolution During Sintering, Journal of the American Ceramic Society, 96 (2013) 103110.

[17] R. Chaim, G. Chevallier, A. Weibel, C. Estournès, Grain growth during spark plasma and flash sintering of ceramic nanoparticles: a review, Journal of Materials Science, 53 (2018) 3087-3105.

[18] M. Thompson, W.G. Fahrenholtz, G. Hilmas, Effect of Starting Particle Size and Oxygen Content on Densification of ZrB2, Journal of the American Ceramic Society, 94 (2011) 429-435.

[19] K. Miyake, Y. Hirata, T. Shimonosono, S. Sameshima, The Effect of Particle Shape on Sintering Behavior and Compressive Strength of Porous Alumina, Materials (Basel, Switzerland)GDC paper 13, 2018.

[20] N.J. Donnelly, T.R. Shrout, C.A. Randall, Properties of (1-x)PZT-xSKN Ceramics Sintered at Low Temperature Using Li2CO3, Journal of the American Ceramic Society, 91 (2008) 2182-2188. 
[21] V. Gil, J. Tartaj, C. Moure, P. Duran, Rapid densification by using Bi2O3 as an aid for sintering of gadolinia-doped ceria ceramics, Ceramics International, 33 (2007) 471-475.

[22] T. Zhu, Y. Lin, Z. Yang, D. Su, S. Ma, M. Han, F. Chen, Evaluation of Li2O as an efficient sintering aid for gadolinia-doped ceria electrolyte for solid oxide fuel cells, Journal of Power Sources, 261 (2014) 255-263.

[23] T.H. T. Hayashi, Piezoelectric properties of low-temperature sintered Pb0.95

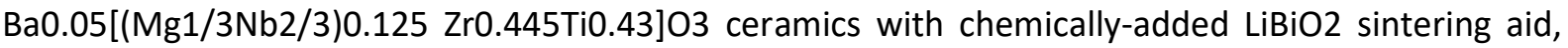
Journal of the European Ceramic Society, 25 (2005) 2437-2441

[24] G. Accardo, C. Ferone, R. Cioffi, Influence of Lithium on the Sintering Behavior and Electrical Properties of Ce0.8Gd0.201.9 for Intermediate-Temperature Solid Oxide Fuel Cells, Energy Technology, 4 (2016) 409-416.

[25] K. Houlberg, E.D. Bøjesen, C. Tyrsted, A. Mamakhel, X. Wang, R. Su, F. Besenbacher, B.B. Iversen, Hydrothermal Synthesis and in Situ Powder X-ray Diffraction Study of Bismuth-Substituted Ceria Nanoparticles, Crystal Growth \& Design, 15 (2015) 3628-3636.

[26] G. Accardo, C. Ferone, R. Cioffi, D. Frattini, L. Spiridigliozzi, G. Dell'Agli, Electrical and Microstructural Characterization of Ceramic Gadolinium-Doped Ceria Electrolytes for ITSOFCs by SolGel Route, Journal of Applied Biomaterials \& Functional Materials, 14 (2016) 35-41.

[27] S. Zha, W. Rauch, M. Liu, Ni-Ce0.9Gd0.101.95 anode for GDC electrolyte-based low-temperature SOFCs, Solid State lonics, 166 (2004) 241-250.

[28] A.I.Y. Tok, L.H. Luo, F.Y.C. Boey, Carbonate Co-precipitation of Gd2O3-doped CeO2 solid solution nano-particles, Materials Science and Engineering: A, 383 (2004) 229-234.

[29] Y.-P. Fu, Microwave-induced combustion synthesis and ionic conductivity of Ce0.8(Gd0.2-xSmx)01.90 ceramics, Ceramics International, 34 (2008) 2051-2057.

[30] F. Aydin, I. Demir, M.D. Mat, Effect of grinding time of synthesized gadolinium doped ceria (GDC10) powders on the performance of solid oxide fuel cell, Engineering Science and Technology, an International Journal, 17 (2014) 25-29.

[31] Y.-M. Su, F.-C. Kung, T.-L. Su, P.-C. Tsai, C.-C. Lai, Y.-L. Kuo, Material characteristics and electric properties of SiO x -doped GDC electrolytes, Journal of the Chinese Institute of Engineers, 34 (2011) 31-38.

[32] R.D.S. Purohit, S.; Tyagi, A. K., Nanocrystalline Ceria Powders Through Citrate-Nitrate Combustion, Journal of Nanoscience and Nanotechnology, 6 (2006).

[33] S. Kulkarni, S. Duttagupta, G. Phatak, Study of glycine nitrate precursor method for the synthesis of gadolinium doped ceria (Ce0.8Gd0.201.90) as an electrolyte for intermediate temperature solid oxide fuel cells, RSC Advances, 4 (2014) 46602-46612.

[34] D.H. Prasad, J.W. Son, B.K. Kim, H.W. Lee, J.H. Lee, Synthesis of nano-crystalline Ce0.9Gd0.101.95 electrolyte by novel sol-gel thermolysis process for IT-SOFCs, Journal of the European Ceramic Society, 28 (2008) 3107-3112.

[35] A. Arabacl, M.F. Öksüzömer, Preparation and characterization of $10 \mathrm{~mol} \% \mathrm{Gd}$ doped CeO2 (GDC) electrolyte for SOFC applications, Ceramics International, 38 (2012) 6509-6515.

[36] G. Kim, N. Lee, K.-B. Kim, B.-K. Kim, H. Chang, S.-J. Song, J.-Y. Park, Various synthesis methods of aliovalent-doped ceria and their electrical properties for intermediate temperature solid oxide electrolytes, International Journal of Hydrogen Energy, 38 (2013) 1571-1587.

[37] N.Q. Minh, Ceramic Fuel Cells, Journal of the American Ceramic Society, 76 (1993) 563-588. [38] S. Medisetti, J. Ahn, S. Patil, A. Goel, Y. Bangaru, G.V. Sabhahit, G.U.B. Babu, J.-H. Lee, H.P. Dasari, Synthesis of GDC electrolyte material for IT-SOFCs using glucose \& fructose and its characterization, Nano-Structures \& Nano-Objects, 11 (2017) 7-12. 
[39] D.H. Prasad, H.-R. Kim, J.-S. Park, J.-W. Son, B.-K. Kim, H.-W. Lee, J.-H. Lee, Superior sinterability of nano-crystalline gadolinium doped ceria powders synthesized by co-precipitation method, Journal of Alloys and Compounds, 495 (2010) 238-241.

[40] V. Gil, J. Tartaj, C. Moure, P. Durán, Sintering, microstructural development, and electrical properties of gadolinia-doped ceria electrolyte with bismuth oxide as a sintering aid, Journal of the European Ceramic Society, 26 (2006) 3161-3171.

[41] A. Moure, J. Tartaj, C. Moure, Synthesis and low-temperature sintering of Gd-doped CeO2 ceramic materials obtained by a coprecipitation process, Journal of the American Ceramic Society, 92 (2009) 2197-2203.

[42] M. Choolaei, Q. Cai, R.C.T. Slade, B. Amini Horri, Nanocrystalline gadolinium-doped ceria (GDC) for SOFCs by an environmentally-friendly single step method, Ceramics International, 44 (2018) 1328613292.

[43] S. Pezeshkpour, A.Z. Abdullah, B. Salamatinia, B. Amini Horri, lonic-gelation synthesis of gadolinium doped ceria (Ce0.8Gd0.201.90) nanocomposite powder using sodium-alginate, Ceramics International, 43 (2017) 7123-7135.

[44] R.C. Maher, V. Duboviks, G.J. Offer, M. Kishimoto, N.P. Brandon, L.F. Cohen, Raman Spectroscopy of Solid Oxide Fuel Cells: Technique Overview and Application to Carbon Deposition Analysis, Fuel Cells, 13 (2013) 455-469.

[45] L.D. Jadhav, M.G. Chourashiya, A.P. Jamale, A.U. Chavan, S.P. Patil, Synthesis and characterization of nano-crystalline Ce1-xGdxO2-x/2 (x=0-0.30) solid solutions, Journal of Alloys and Compounds, 506 (2010) 739-744.

[46] R.D. Gould, S. Kasap, A.K. Ray, Thin films, Springer Handbook of Electronic and Photonic Materials, Springer2017, pp. 1-1.

[47] M. Darroudi, S.J. Hoseini, R. Kazemi Oskuee, H.A. Hosseini, L. Gholami, S. Gerayli, Food-directed synthesis of cerium oxide nanoparticles and their neurotoxicity effects, Ceramics International, 40 (2014) 7425-7430.

[48] H.-J. de Jager, L.C. Prinsloo, The dehydration of phosphates monitored by DSC/TGA and in situ Raman spectroscopy, Thermochimica Acta, 376 (2001) 187-196.

[49] H. Valdes-Espinosa, E.M. Stuve, S.B. Adler, Modeling Water Reduction on 10 Mole\% GadoliniaDoped Ceria (GDC10) Porous Electrodes, ECS Transactions, 66 (2015) 229-251.

[50] K. Nagy, I. Dékány, Preparation of nanosize cerium oxide particles in W/O microemulsions, Colloids and Surfaces A: Physicochemical and Engineering Aspects, 345 (2009) 31-40.

[51] A. Zarkov, A. Stanulis, T. Salkus, A. Kezionis, V. Jasulaitiene, R. Ramanauskas, S. Tautkus, A. Kareiva, Synthesis of nanocrystalline gadolinium doped ceria via sol-gel combustion and sol-gel synthesis routes, Ceramics International, 42 (2016) 3972-3988.

[52] D.W. Ni, V. Esposito, S.P.V. Foghmoes, S. Ramousse, Densification and grain growth kinetics of Ce0.9Gd0.101.95 in tape cast layers: The influence of porosity, Journal of the European Ceramic Society, 34 (2014) 2371-2379.

[53] J.P. Grilo, D.A. Macedo, R.M. Nascimento, F.M. Marques, Electronic conductivity in Gd-doped ceria with salt additions, Electrochimica Acta, 318 (2019) 977-988.

[54] R.O. Fuentes, R.T. Baker, Synthesis and properties of Gadolinium-doped ceria solid solutions for IT-SOFC electrolytes, International Journal of Hydrogen Energy, 33 (2008) 3480-3484.

[55] T. Hsieh, D. Ray, Y. Fu, Co-precipitation synthesis and AC conductivity behavior of gadoliniumdoped ceria, Ceramics International, 39 (2013) 7967-7973.

[56] SOLID OXIDE FUEL CELLS : materials properties and performance, CRC Press, [Place of publication not identified, 2019. 
[57] V.T. DS, P.R. Padala, U. Renju, Influence of aliovalent cation substitution on structural and electrical properties of Gd 2 ( $\mathrm{Zr} 1-x \mathrm{M} \mathrm{x}) 20$ 7- $\delta(\mathrm{M}=\mathrm{Sc}, \mathrm{Y})$ systems, RSC Advances, 5 (2015) 8867588685.

[58] M.F. Öksüzömer, G. Dönmez, V. Sariboğa, T.G. Altinçekiç, Microstructure and ionic conductivity properties of gadolinia doped ceria ( $\mathrm{GdxCe1}-\mathrm{xO2}-\mathrm{x} / 2$ ) electrolytes for intermediate temperature SOFCs prepared by the polyol method, Ceramics International, 39 (2013) 7305-7315.

[59] A. Sin, Y. Dubitsky, A. Zaopo, A. Arico, L. Gullo, D. La Rosa, S. Siracusano, V. Antonucci, C. Oliva, O. Ballabio, Preparation and sintering of $\mathrm{Ce} 1-\mathrm{xGdxO2}-\mathrm{x} / 2$ nanopowders and their electrochemical and EPR characterization, Solid State lonics, 175 (2004) 361-366.

[60] A.Z. Liu, J.X. Wang, C.R. He, H. Miao, Y. Zhang, W.G. Wang, Synthesis and characterization of Gd0. 1Ce0. 901.95 nanopowder via an acetic-acrylicmethod, Ceramics International, 39 (2013) 6229-6235. [61] D. Ding, B. Liu, M. Gong, X. Liu, C. Xia, Electrical properties of samaria-doped ceria electrolytes from highly active powders, Electrochimica Acta, 55 (2010) 4529-4535.

[62] C. Tian, S.-W. Chan, lonic conductivities, sintering temperatures and microstructures of bulk ceramic CeO2 doped with Y2O3, Solid State lonics, 134 (2000) 89-102. 